\title{
MEDIDAS DE DESEMPEÑO Y EFICIENCIA DEL GASTO EN EL SECTOR PUBLICO DESCENTRALIZADO. EL CASO DE BOLIVIA*
}

\author{
PERFORMANCE AND EFFICIENCY MEASURES IN \\ THE PUBLIC SECTOR. THE CASE OF BOLVIA
}

\section{ALBERTO PORTO**}

porto.alb@gmail.com

\section{MARCELO GARRIGA**}

marcelogarriga@yahoo.com.ar

\section{WALTER ROSALES **}

walter75@yahoo.com

\begin{abstract}
The aim of this paper is to conceptually present measures of performance, cost and efficiency of the public sector and quantify them for various services in the Estado Plurinacional de Bolivia. As in all applied research, the work has limitations that originate, fundamentally, in the lack of information. But using the available information some results are obtained that can be challenged in future research. The quantifications show important improvements between 1992 and 2012. In this period, the vertical structure of the general government of Bolivia underwent a profound transformation originated in the process of fiscal decentralization. Expenditure from subnational government levels (departments and municipalities) doubled its share in total spending between 1990 and 2012 and municipal participation went from approximately one third of subnational spending to approximately two thirds. The preliminary conclusion of this work is the existence of a positive relationship between performance in the health, education, and housing
\end{abstract}

* Se agradecen los comentarios de Huáscar Eguino y Carlos Lora (BID) y los recibidos en las IV Jornadas Iberoamericanas de Financiación Local, CEPAL, Santiago de Chile, 2015. Los errores son de exclusiva responsabilidad de los autores.

** Depto. de Economía, Facultad de Ciencias Económicas, Universidad Nacional de La Plata. Calle 6 e/ 47 y 48, $5^{\circ}$ Piso, oficina (516), (1900) La Plata, Argentina. Tel-fax: 54-221-4229383. Correspondig autor: Alberto Porto (porto.alb@gmail.com) 
and urban services sectors and decentralization. With the improvement in performance also increased the political participation of citizens so that it can be concluded, preliminarily, that the country moved in one of the positive intervals of the federalism frontier of Inman and Rubinstein.

Keywords: Fiscal performance, efficiency, decentralization, public spending.

JEL Classification: $H 5, H 7$.

\section{Resumen}

El objetivo de este trabajo es presentar conceptualmente medidas de desempeño, costo y eficiencia del sector público y cuantificarlas para varios servicios en el Estado Plurinacional de Bolivia. Como en toda investigación aplicada, el trabajo tiene limitaciones que se originan, fundamentalmente, en la falta de información. Pero utilizando la información disponible llega a resultados que pueden ser contrastados en futuras investigaciones. Las cuantificaciones muestran mejorías importantes entre 1992 y 2012. En ese período la estructura vertical del gobierno general de Bolivia sufrió una profunda transformación originada en el proceso de descentralización fiscal. El gasto de los niveles de gobierno subnacionales (departamentos y municipalidades) duplicó su importancia dentro del gasto total entre 1990 y 2012. Dentro del sector subnacional también se verificó una importante descentralización: la participación municipal pasó de aproximadamente un tercio del gasto subnacional a alrededor de dos tercios entre esos mismos años. La conclusión preliminar de este trabajo es la existencia de relación positiva entre el desempeño en los sectores salud, educación, y vivienda y servicios urbanos y la descentralización. Con la mejora en el desempeño aumentó también la participación política de los ciudadanos, de modo que puede concluirse, preliminarmente, que el país se movió en uno de los intervalos positivos de la frontera del federalismo de Inman y Rubinstein.

Palabras clave: Desempeño fiscal, eficiencia, descentralización, gasto público.

Clasificación JEL: H5, H7.

\section{INTRODUCCION}

El objetivo de este trabajo es presentar medidas parciales de calidad del sector público y cuantificarlas para el caso del Estado Plurinacional de Bolivia1. Medir la

1 En adelante, para simplificar, se usarán indistintamente Estado Plurinacional de Bolivia y Bolivia. 
calidad del sector público es un tema de gran complejidad porque depende de los objetivos del gobierno. La medición de la calidad en un estado de servicios es distinta a la medición en un estado de bienestar -que agrega a la prestación de servicios el objetivo de corregir la distribución del ingreso que resulta del mercado y la atención de las necesidades de determinados grupos de personas (desempleados, edad avanzada, problemas especiales de salud, entre otros)-. La teoría económica brinda instrumentos para medir en forma objetiva la calidad del sector público en el estado de servicios, cosa que no ocurre con el estado de bienestar, ya que sus objetivos dependen de juicios de valor (Musgrave, 1996; Tanzi, 1999).

Los conceptos de eficiencia, productividad y calidad aplicados al sector público pueden ser dimensiones difíciles de medir. Tanzi (1999) define la calidad del sector público como las "características que permiten que el gobierno persiga sus objetivos en la forma más eficiente". Diferencia entre calidad del sector público y calidad de la política económica: un sector público de alta calidad puede estar acompañado de mala calidad de la política económica si se promueven pobres medidas de gobierno. Sin embargo, es de esperar que exista una relación directa debido a que un sector público de alta calidad facilita la formulación y ejecución de buenas políticas. La calidad del sector público comprende las reglas constitucionales y legales, las regulaciones, la calidad de las instituciones públicas, los mecanismos de control y las reglas para el cumplimiento de los contratos, y la eficiencia. La cuantificación de cada uno de esos componentes plantea serias dificultades. La Porta et al. (1998) miden la "calidad del gobierno" definida como "buen gobierno para el desarrollo capitalista". Utilizan proxies (por separado) para las dimensiones intervencionismo, eficiencia del sector público, calidad de la provisión de los bienes públicos, tamaño del gobierno y libertad política. En el trabajo presente se utiliza la dimensión eficiencia del sector público. Una forma de medirla (Gupta et al., 1997) es relacionando el gasto en cada actividad del gobierno (p.ej. salud, educación) y el resultado de ese gasto (ver sección III). Atkinson $(2005)^{2}$ realiza una aplicación particular para medir el output y la productividad del sector público en las cuentas nacionales del Reino Unido. Diferencia los insumos y gasto del sector público (inputs) de los resultados de la actividad gubernamental.

La medición de eficiencia en este trabajo se aplica al sector público de Bolivia, que ha tenido grandes transformaciones en los últimos treinta años. Para citar las más importantes: (i) el retorno a la democracia en 1982; (ii) la Ley de Participación Popular en 1994, que aumentó significativamente la descentralización fiscal por la vía de la creación de municipios territorializados y aumentó las transferencias hacia ese nivel de gobierno (que pasaron del 10\% al 20\% de los recursos coparticipables); (iii) el cambio de gobierno en 2006 y la reforma de la

2 Ver también el comentario de Aled ab Iorwerth (2006). 
Constitución en el $2009^{3}$. A la complejidad conceptual del tema se agregan, como en toda investigación aplicada, las limitaciones que se originan, fundamentalmente, en la falta de información ${ }^{4}$.

El trabajo está organizado en la forma siguiente. En la Sección II se presenta una breve descripción de la estructura del sector público boliviano en los últimos veinte años y las reformas institucionales que influyeron en las funciones del gobierno. La Sección III brinda un marco conceptual y la metodología para la construcción de indicadores. En la Sección IV se cuantifican los indicadores de desempeño, gasto y eficiencia. En la Sección V se discuten los resultados y se concluye.

\section{EL PROCESO DE DESCENTRALIZACION EN BOLIVIA}

\section{Aspectos cuantitativos del proceso de descentralización}

La Figura 1 y las Tablas 12 y 13 del Anexo documentan la evolución del tamaño y la estructura vertical del sector público ${ }^{5}$ de Bolivia entre 1990 y 2012. Entre esos años el gasto del sector público no financiero (incluyendo las actividades empresarias del Estado) pasó del 35,1\% del producto interno bruto (PIB) al 45,3\%. El gasto del gobierno general (que no incluye a las empresas públicas) representó el 22,3\% del producto en 1990 y pasó al 33,2\% en 2012. La diferencia entre las mediciones se explica por las empresas públicas, cuya importancia varió a lo largo del período: hasta 1994 representaron alrededor del 11,6\% del PIB, en el período 1994-2006 disminuyeron al $5,6 \%$ del PIB y desde el 2006 en adelante, debido a las estatizaciones y el incremento del precio de los hidrocarburos, pasaron al 11,7\% del PIB.

La estructura del gobierno general sufrió una profunda transformación originada en el proceso de descentralización fiscal. El gasto de los niveles de gobierno subnacionales (departamentos y municipalidades) duplicó su importancia dentro del gasto total entre los años extremos. Dentro del sector subnacional también se verificó una importante descentralización: la participación municipal pasó de aproximadamente un tercio del gasto subnacional a alrededor de dos tercios. Uno de los objetivos de este trabajo es

3 La Porta et al. (1998) presentan evidencia acerca de las diferencias en la calidad del gobierno entre los países y de la influencia sistemática de las circunstancias históricas, capturadas por las heterogeneidades étnico-lingüísticas, orígenes legales y religión.

4 De particular importancia en el caso de Bolivia es que los tres niveles de gobierno operan en los mimos sectores, no quedando claramente delimitadas las responsabilidades de cada uno de ellos. Para detalles ver la Sección 2.3.

5 El sector público no financiero comprende al gobierno general y las empresas públicas (nacionales y de servicios de agua locales o municipales). El gobierno general está compuesto por el gobierno central (que incluye las universidades), los gobiernos autónomos departamentales, los gobiernos autónomos municipales y la seguridad social (cajas de salud, seguros de salud, e instituciones de seguridad social). 


\section{FIGURA 1}

\section{TAMAÑO Y ESTRUCTURA VERTICAL (DESCENTRALIZACION) DEL SECTOR PUBLICO DE BOLIVIA}

(1990-2012). EN \%
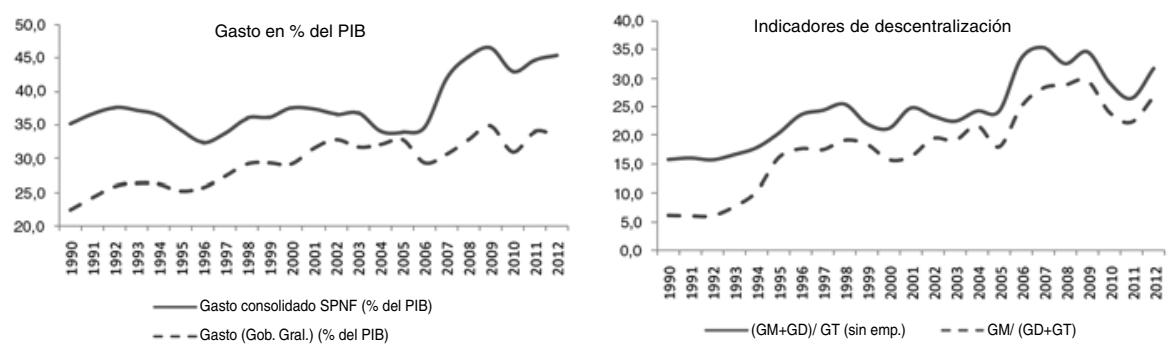

Fuente: Elaboración propia a base de datos del dossier fiscal del Ministerio de Economía y Finanzas de Bolivia y del Anuario estadístico de UDAPE.

Referencias: GM: gobiernos municipales; GD: gobiernos departamentales; GC: gobierno central.

estudiar si esta profunda modificación afectó, y en qué dirección, la eficiencia en la provisión de bienes públicos y cuasipúblicos.

\section{Tres reformas institucionales y un hecho exógeno}

\subsection{El retorno a la democracia en 1982}

Luego de varias revoluciones y golpes de Estado militares se reinstaura la democracia como forma de gobierno en 1982. Es un cambio importante en la vida de Bolivia pese a distintas turbulencias hasta su consolidación. La vuelta a la democracia se origina en la síntesis de múltiples factores (históricos, políticos y sociales), siendo el resultante de la voluntad de toda la comunidad.

Sin embargo, el contexto socioeconómico en el que se restauró la democracia no fue favorable, caracterizándose por una marcada caída del PIB y de los precios de los minerales, y un alto nivel de endeudamiento e inflación. El primer gobierno democrático en esta etapa tuvo un débil manejo de la crisis económica, derivando en una crisis política que finalizó con un llamado anticipado a elecciones. La política social en este período se enfocó en la aplicación de programas de emergencia que atenuaron los efectos de la crisis económica que repercutía fundamentalmente en los sectores más pobres del país (Loayza, Santa Cruz y Pereira, 1999).

Los gobiernos que le sucedieron tuvieron como objetivo la estabilización macroeconómica y la consolidación del proceso democrático. En materia social, se 
planteó la Estrategia Social Boliviana, en la que se redireccionaba el gasto público social en la lucha contra la pobreza. El financiamiento por medio de donaciones internacionales fue una fuente clave.

Probablemente, una vez alcanzada cierta estabilidad socioeconómica, se dieron las condiciones que permitieron avanzar en el proceso de descentralización, tema que estaba en la agenda de la sociedad desde el origen de la república (Zuazo, Faguet y Bonifaz, 2012).

\subsection{La ley de participación popular (1994)}

Entre 1994 y 1996 se produjo el avance más significativo en el camino hacia la descentralización y las autonomías locales al aprobarse la Ley de Participación Popular (Mesa Gilbert, 2012). Zuazo, Faguet y Bonifaz (2012) consideran que "la Ley de Participación Popular de 1994 fue una forma de descentralización radical y repentina hacia los municipios rurales, mediante la creación de municipios en el área rural y la descentralización de importantes recursos a los mismos".

Esta ley impulsa la creación de los municipios territorializados, y la elección de sus autoridades por el voto popular de sus autoridades ${ }^{6}$. Les asigna de modo directo un porcentaje muy significativo de los ingresos coparticipables del gobierno central (20\% vs. $10 \%$ hasta ese momento). A su vez, crea el concepto de autonomías con responsabilidades y competencias específicas. Fue también el embrión de las autonomías indígenas.

La Ley de Participación Popular introduce cuatro cambios fundamentales (Seemann, 2004):

1) Institucionalización de las relaciones entre la sociedad civil y el Estado boliviano, por intermedio de las Organizaciones Territoriales de Base (OTB): 12.000 rurales y 8.000 organizaciones barriales. Estas organizaciones participan en el planeamiento municipal y la prestación de los servicios de salud y educación. Las OTB supervisan los servicios municipales, participan en las audiencias públicas, controlan el gasto municipal y tienen la responsabilidad de opinar respecto de las decisiones de desarrollo y reclamar por el cumplimiento de las leyes financieras y ambientales. El hecho más revolucionario es el reconocimiento por primera vez de una sociedad multicultural. Adicionalmente se establecen Comités de Vigilancia en cada Municipalidad. Su principal función es promover una efectiva relación entre los gobiernos municipales y las OTB, controlar los gastos de los gobiernos municipales y asegurar que los recursos se distribuyan igualitariamente entre

6 A partir de 1987 se realizan elecciones de autoridades locales, pero como señala Zuazo (2012), solo tenían interés político las elecciones realizadas en 9 capitales departamentales. Los municipios de áreas rurales carecían de recursos y por tanto de poder de decisión. A partir de la Ley de Participación Popular se llevan a cabo elecciones en todas las municipalidades. 
las áreas rurales y urbanas. El papel de estas organizaciones es considerado por Faguet (2012) uno de los principales determinantes del desempeño diferencial de los gobiernos municipales.

2) Alentó la municipalización dando lugar a la creación de nuevos municipios, alcanzando a 311 municipios, cada uno con poder sobre su territorio, donde sus autoridades son elegidas por voto popular. Además, se transfieren competencias en áreas esenciales como salud, educación, desarrollo económico local, caminos vecinales, microrriego, cultura, deportes y medio ambiente. Previo a esta ley, existían alrededor de 100 municipios legalmente constituidos, pero solo 30 de ellos existían en un "sentido funcional". Solo estos municipios contaban con un presupuesto que ejecutaban. Las decisiones locales eran tomadas a nivel central o en cada departamento (Sánchez de Lozada y Faguet, 2014).

3) Distribución de los recursos de coparticipación entre el gobierno central y las municipalidades en función de la población de cada gobierno local (en lugar de ser distribuidos en función de criterios políticos). Los fondos transferidos pasan de 10 a $20 \%$ de los recursos tributarios coparticipables. Previo a esta ley, la distribución de fondos se caracterizaba por notorias disparidades: según Faguet (2004), en 1993 las ciudades de La Paz, Santa Cruz y Cochabamba recibían el $86 \%$ de la coparticipación nacional, porcentaje que se redujo al 27\% en 1995 luego de la LPP. Las capitales de los nueve departamentos recibían el 93\%; el 7\% le correspondía al resto de los municipios. En igual sentido se produjo un cambio notable en la distribución territorial de los fondos y de la inversión (financiada con la coparticipación).

4) Se reorganiza el gobierno central para dar cumplimiento a las regulaciones establecidas en la ley. En particular, las unidades de desarrollo regional del gobierno central se reorganizan para dar apoyo a los gobiernos locales.

En síntesis, la Ley de Participación Popular representa un hito en el proceso de descentralización del Estado boliviano. Esta ley jerarquiza a los gobiernos locales dotándolos de competencias y de mayores recursos distribuidos por medio de criterios objetivos. La pregunta intrigante es por qué un Presidente (Sánchez de Lozada) decide descentralizar, transfiriendo poder y recursos a otros niveles de gobierno, en un país con antecedentes fuertemente centralista. Su respuesta fue: I realized two things 1) Only the people who have the problems know the solutions, and (2) An idiot close to the problems is better than a genius a thousand miles away. If he's felling the pain, he'll know the solution better than anyone. So I went into this violent effort to decentralize power in Bolivia (Sánchez de Lozada y Faguet, 2014) ${ }^{7}$. Se trata de una versión del Teorema de la descentralización de Oates (1972).

7 Acerca de la descentralización como una solución estructural a exigencias políticas, aplicado al caso de Bolivia, ver Shami y Fauget, 2015). 
2.3. Reformas impulsadas por el gobierno que asume a partir de 2006 y la nueva Constitución Política de 2009

A partir de 2006 se dota de mayor poder a la población indígena y se redirecciona la política fiscal hacia mayor gasto público "social" con características redistributivas. También se modifica el régimen impositivo y los mecanismos de distribución de fondos a los departamentos, universidades y municipalidades ${ }^{8}$.

La nueva Constitución Política (2009) da un paso político-social de importancia al reconocer a las naciones y pueblos indígenas originarios campesinos. Esta norma fundamental consagra los principios rectores que rigen la organización territorial, y la autonomía de los gobiernos departamentales, municipales y de los pueblos originarios. La Constitución Política se complementa luego con la sanción de la ley marco de Autonomías y Descentralización (2010), que regula el régimen de autonomías y las bases de la organización territorial ${ }^{9}$.

\subsection{Un hecho exógeno}

Un hecho exógeno a Bolivia pero con gran impacto económico y para el diseño de políticas públicas ha sido el notable crecimiento del precio de los hidrocarburos (en particular del gas), que significó al país un importante ingreso de divisas y para el gobierno un gran incremento de sus recursos fiscales. En 2012 el precio del gas fue más de 10 veces el de 2003; los ingresos tributarios por hidrocarburos pasaron del 4,6\% del PIB en 2003 al 11,7\% en 2012 (ver Tabla 14 del Anexo).

\section{La asignación de responsabilidades de gasto en los principales sectores: salud, educación y servicios urbanos}

La asignación de funciones entre niveles de gobierno se encuentra establecida en la Constitución Política y Ley Marco de Autonomías y Descentralización № 031 de 2010.

La Constitución Política en el capítulo octavo establece la distribución de competencias, distinguiendo entre: (a) Privativas, aquellas cuya legislación, reglamentación y ejecución no se transfiere ni delega, y están reservadas para el

8 En 2005, la Ley de Hidrocarburo 3.058 introduce el impuesto directo a los hidrocarburos (IDH), cuya distribución está orientada a fomentar el desarrollo productivo local y profundizar el proceso de descentralización en el marco del Plan Nacional de Desarrollo. La distribución del producido de la explotación de recursos naturales introduce modificaciones en la distribución de los fondos, alejándolo de la igualdad per cápita consagrada en la LPP. La redistribución del IDH se convirtió en uno de los temas centrales del diálogo nacional (octubre de 2008).

9 La Nueva Constitución Política del Estado (NCPE) establece que una Ley Marco de Autonomía y Descentralización deberá regular el procedimiento para la elaboración de estatutos autonómicos y cartas orgánicas, la transferencia y delegación de competencias, el régimen económico financiero y la coordinación entre el nivel central y las entidades territoriales descentralizadas y autónomas (Art. 271). Este mandato se cumplió con la sanción de la Ley Nº31, de julio de 2010. 
nivel central del Estado; (b) Exclusivas, aquellas en las que un nivel de gobierno tiene respecto de una determinada materia las facultades legislativa, reglamentaria y ejecutiva, pudiendo transferir y delegar estas dos últimas; (c) Concurrentes, aquellas en las que la legislación corresponde al nivel central del Estado y los otros niveles ejercen simultáneamente las facultades reglamentaria y ejecutiva; y (d) Compartidas, aquellas sujetas a una legislación básica de la Asamblea Legislativa Plurinacional cuya legislación de desarrollo corresponde a las entidades territoriales autónomas, de acuerdo con su característica y naturaleza.

La Ley $\mathrm{N}^{\circ} 031$ establece las responsabilidades para cada nivel de gobierno, incluyendo a los gobiernos indígenas originarios campesinos. En general le asigna al gobierno central la rectoría, planificación y la elaboración de políticas a nivel nacional. Confiere a los gobiernos departamentales la administración y gestión de los recursos y a los gobiernos locales la administración de la infraestructura (básicamente de establecimientos educativos y sanitarios), y la provisión de bienes y servicios locales (por ejemplo, agua potable y alcantarillado).

En la práctica, la interacción entre los tres niveles de gobierno es más compleja, operan concurrentemente en determinados sectores, no quedando claramente delimitadas las responsabilidades de cada nivel.

La Tabla 1 muestra la asignación de responsabilidades de gasto entre niveles de gobierno.

\section{MARCO CONCEPTUAL Y METODOLOGIA}

Los estudios de medición del desempeño del sector público han seguido distintos enfoques (Gupta et al., 1997). En un primer enfoque se han utilizado medidas por el lado de los insumos para proveer bienes: cantidad de empleados en cada actividad, gasto en cada actividad, etc. Estas medidas adolecen de fallas, ya que pueden existir ineficiencias traducidas en empleo, gasto, etc., que quedan ocultas en las medidas. En un segundo enfoque se ha utilizado la producción de bienes. Un tercer enfoque ha utilizado los resultados de las actividades del gobierno. Estos enfoques son parciales, ya que consideran por separado insumos, o productos, o resultados.

En este trabajo se consideran simultáneamente los outcomes (resultados) y los inputs (gasto realizado en cada actividad). Se sigue la metodología propuesta inicialmente por Tanzi et al. (1997) y Afonso et al. (2003) que definen el desempeño y la eficiencia del sector público. El desempeño se mide con indicadores que representan las oportunidades que brinda el gobierno a los ciudadanos resultantes de la provisión de bienes (indicadores de resultados en salud, educación, infraestructura, etc.) ${ }^{10}$. Para cada indicador de desempeño se considera el gasto en esa finalidad. La razón

10 Afonso et al. agrega los indicadores musgravianos que reflejan el comportamiento del sector público en las ramas de asignación, estabilización y distribución de Musgrave (1959). 


\section{TABLA 1}

\section{ASIGNACION DE RESPONSABILIDADES ENTRE NIVELES DE GOBIERNO EN LOS SECTORES DE SALUD, EDUCACION Y SERVICIOS URBANOS}

\begin{tabular}{|c|c|c|c|}
\hline $\begin{array}{l}\text { Nivel de } \\
\text { gobierno }\end{array}$ & Educación & Salud & $\begin{array}{l}\text { Servicios urbanos (agua } \\
\text { potable y alcantarillado) }\end{array}$ \\
\hline 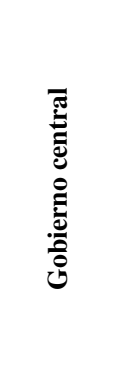 & $\begin{array}{l}\text { Por medio del Ministerio } \\
\text { de Educación y sus } \\
\text { viceministerios, es responsable } \\
\text { de las políticas y estrategias } \\
\text { educativas y de las políticas } \\
\text { de administración y gestión } \\
\text { educativa y curricular. En la } \\
\text { práctica, también se encarga } \\
\text { de los recursos humanos } \\
\text { (selección, contratación, } \\
\text { política salarial). }\end{array}$ & $\begin{array}{l}\text { Coordinación, elaboración de } \\
\text { políticas sanitarias nacionales, } \\
\text { fijar normas generales, } \\
\text { planificación, rectoría del } \\
\text { sistema único de salud y } \\
\text { garantizar su funcionamiento. } \\
\text { En la práctica, es responsable } \\
\text { de la contratación y despido } \\
\text { de personal. Además de fijar } \\
\text { la política salarial. }\end{array}$ & $\begin{array}{l}\text { Formular y aprobar el } \\
\text { régimen de políticas, planes } \\
\text { y programas de servicios } \\
\text { básicos a nivel país, elaborar } \\
\text { y financiar subsidiariamente } \\
\text { proyectos de alcantarillado } \\
\text { y agua potable con otros } \\
\text { niveles autonómicos. }\end{array}$ \\
\hline 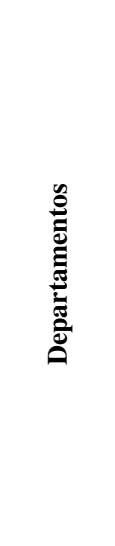 & $\begin{array}{l}\text { Mediante las Direcciones } \\
\text { De e part a m e n tales de } \\
\text { Educación les corresponde la } \\
\text { implementación de las políticas } \\
\text { educativas y de administración } \\
\text { curricular en el departamento, } \\
\text { así como la administración y } \\
\text { gestión de los recursos en el } \\
\text { ámbito de su jurisdicción. Son } \\
\text { responsables de dotar, financiar } \\
\text { y garantizar los servicios } \\
\text { básicos, infraestructura, } \\
\text { mobiliario, material educativo } \\
\text { y equipamiento a los Institutos } \\
\text { Técnicos y Tecnológicos en su } \\
\text { jurisdicción. }\end{array}$ & $\begin{array}{l}\text { Formular, junto con el nivel } \\
\text { central, planes de salud, } \\
\text { infraestructura y equipamiento } \\
\text { de efectores del tercer nivel } \\
\text { de complejidad, coordinar } \\
\text { políticas y acciones con los } \\
\text { municipios y universidades, } \\
\text { cofinanciar políticas y planes } \\
\text { de salud con el nivel central } \\
\text { de gobierno y entidades } \\
\text { territoriales autónomas. }\end{array}$ & $\begin{array}{l}\text { Elaborar, financiar y ejecutar } \\
\text { subsidiariamente planes y } \\
\text { proyectos de agua potable } \\
\text { y alcantarillado en conjunto } \\
\text { con otros niveles de gobierno, } \\
\text { colaborar con la asistencia } \\
\text { técnica. }\end{array}$ \\
\hline 莺 & $\begin{array}{l}\text { Son responsables de dotar, } \\
\text { financiar y garantizar } \\
\text { los servicios básicos, } \\
\text { infraestructura, mobiliario, } \\
\text { material educativo y } \\
\text { equipamiento de las } \\
\text { Unidades Educativas de } \\
\text { Educación Regular, Educación } \\
\text { Alternativa y Especial, así } \\
\text { como de las Direcciones } \\
\text { Distritales y de Núcleo, en } \\
\text { su jurisdicción. }\end{array}$ & $\begin{array}{l}\text { Administrar infraestructura } \\
\text { y e qu i p a mi e n to de } \\
\text { establecimientos de primer } \\
\text { y segundo nivel. Ejecutar } \\
\text { las políticas de salud e } \\
\text { implementar el sistema único } \\
\text { de salud en su jurisdicción. }\end{array}$ & $\begin{array}{l}\text { Ejecutar programas y } \\
\text { proyectos. Elaborar, financiar } \\
\text { y ejecutar proyectos de agua } \\
\text { potable. Proveer servicios de } \\
\text { agua potable y alcantarillado. }\end{array}$ \\
\hline
\end{tabular}

Fuente: Elaboración propia a base de Ley 031 de 2010, Burky y otros (1999) y Ahmad y García-Escribano (2010). 
de los indicadores de desempeño y de gasto en cada finalidad relacionada constituye un indicador de eficiencia de cada país o provincia/municipio. El índice global de eficiencia es la sumatoria ponderada de los indicadores seleccionados. Se puede medir para un año o en un enfoque dinámico para años separados. En la misma línea, la OCDE (2015) ilustra las etapas que componen las actividades gubernamentales: (i) inputs (cuántos y qué tipo de insumos utiliza); (ii) procesos (qué y cómo); (iii) outputs (bienes y servicios que produce el gobierno); (iv) outcomes (el impacto de la actividad del gobierno en los ciudadanos) $)^{11}$.

Para fijar ideas se presenta un desarrollo analítico simple. Se supone que los argumentos de la función de bienestar social, $W$, son los indicadores socioeconómicos $\left(X_{j}\right)$ que miden outcomes (resultados) en los sectores educación, salud, infraestructura, etc., en los que el sector público está involucrado en la producción $\left(P_{j}\right)$,

$$
W=W\left[\left(X_{1}\left(P_{1}\right), X_{2}\left(P_{2}\right), \ldots \ldots, X_{j}\left(P_{j}\right)\right]\right.
$$

Con $d W / d X_{j}>0 \mathrm{y} \mathrm{d}^{2} \mathrm{~W} / d X_{j}^{2}<0$.

El gobierno gasta $\left(G_{j}\right)$ en insumos utilizados en la producción $\left(P_{j}\right)$ para obtener resultados $X_{j}(j=1 \ldots . . J)$ que brindan bienestar social. Tres preguntas importantes son:

i) Cuál es el impacto sobre el bienestar, en cada sector y total, del outcome $X_{j}$ del output $\left(P_{j}\right)$ sector público;

ii) Cuál es el gasto $\left(G_{j}\right)$ en inputs utilizados en la producción $\left(P_{j}\right)$ en cada sector y el gasto total;

iii) Cuál es la eficiencia (relación entre i) y ii)) en cada sector y la total.

Resumiendo: el gobierno utiliza factores productivos para obtener niveles de producción de distintos bienes $\left(P_{j}\right)^{12}$ que dan lugar a resultados $\left(X_{j}\right)$ que se ponderan con $a_{j}$ en la función de bienestar, siendo $\left(\sum a_{j}=1\right)$. El impacto sobre $W$ viene dada por

$$
W_{i}=\sum\left(a_{j}\right) \cdot\left(X_{i j}\left(P_{i j}\right)\right)
$$

El gasto realizado en cada sector $j$ es $\left(G_{i j}\right)$ y el total

$$
G_{i}=\sum G_{i j}\left(P_{i j}\right)
$$

11 Bradford, Malt y Oates (1969) utilizan las denominaciones inputs, "D” ouptut y "C" output. El gobierno utiliza factores productivos (inputs) para producir el "D" output que es la producción directa de bienes y servicios; ese output, en general difiere del "C" output, que es el que demandan los ciudadanos (outcomes). Un ejemplo es el siguiente: el "D" ouptut es el número de días u horas de clase; el "C" output es el grado de conocimientos adquiridos por los alumnos.

12 Hay una función de producción que relaciona la cantidad de insumos y sus precios con los niveles de producción $P_{j}$. En la función de bienestar del texto los argumentos son los $X_{j}$ (outcomes) y no los $P_{j}$ (outputs). 
La eficiencia en cada sector es $E_{i j}=\left(W_{i j} / G_{i j}\right)$ siendo la eficiencia global

$$
E_{i}=\sum\left(b_{j}\right) .\left(W_{i j} / G_{i j}\right)
$$

Las $b_{j}$ son las ponderaciones de la eficiencia de cada sector, con $\Sigma b_{j}=1$. El cambio en la eficiencia $\left(\Delta E_{i}\right)$ ante un cambio en $P_{1}\left(d P_{1}\right)$ resulta de

$$
\Delta W / \Delta G_{1}=\left[\left(d W / d X_{1} \cdot d X_{1} / d P_{1}\right)\right] /\left(\Delta G_{1} / d P_{1}\right)=\text { variación en W/variación en } G_{1}
$$

donde, para simplificar, se supone que todos los precios de los insumos han sido normalizados a la unidad y no se modifican a lo largo del período.

El subíndice i puede utilizarse, por un lado, para indicar distintos años y un mismo nivel de gobierno; por otro lado, pude indicar distintos países o distintos niveles del gobierno para un año dado; finalmente, puede utilizarse una combinación de los dos criterios.

Como se expresó antes, las medidas consideradas usualmente para medir el desempeño del gobierno son las que centran la atención en los insumos o gastos $\left(G_{i j}\right)$, o en el output, o en el outcome. Este trabajo agrega la eficiencia $\left(E_{i j}\right)$ que considera tanto el impacto sobre $W_{i j}$ como sobre $G_{i j}$.

Es importante notar que mucha de la bibliografía aplicada reciente, que estudia el impacto de las políticas públicas y las acciones gubernamentales, se limita a los resultados. De esa forma se mide el beneficio de una política sin considerar los costos. Es un enfoque parcial, útil como primer paso, pero que tomado aisladamente puede llevar a conclusiones erróneas: una política puede tener un beneficio positivo pero con costos mayores, de modo que el beneficio neto sea negativo. Si solo se mira el lado del beneficio puede recomendarse la expansión de esas actividades que son ineficientes desde el punto de vista económico. Es necesario agregar el costo de las políticas y recordar a Pigou (1947) respecto de los costos relevantes: los costos directos (lo que paga el contribuyente al Estado) y los indirectos (los costos administrativos del Estado y de los contribuyentes, más el costo de eficiencia de los impuestos por las distorsiones que originan en la asignación de recursos. En este trabajo se miden los beneficios, los costos y la eficiencia definida como la relación entre esas dos medidas.

\section{CUANTIFICACIONES}

\section{Desempeño, gastos y eficiencia para el sector público consolidado}

En esta sección se cuantifican indicadores de desempeño del sector público consolidado, considerando los tres niveles de gobierno (central, departamental y municipal). Los indicadores de desempeño, junto con los de gasto público, permiten obtener los indicadores de eficiencia definidos en la Sección III ${ }^{13}$.

13 No se cuenta con la información para la medición de la eficiencia productiva (relación de inputs a outputs). El número de observaciones tampoco permite realizar estimaciones, ya que son datos de nueve departamentos y tres censos. 
Se recurre a la información estadística disponible para la construcción de los indicadores de desempeño, comparando datos del último censo (2012) con datos de los censos anteriores de 1992 y 2001. Los datos censales de 1992 son ilustrativos del período previo a la Ley de Participación Popular. Los otros dos años reflejan las situaciones pre y postincremento del precio del gas. En cuanto a los indicadores de gasto, la principal limitación es que la mayoría de los gobiernos locales se crean a partir de la ley, con lo que no se dispone de información para la comparación del período anterior y posterior a la ley. Por otra parte, es posible destacar que se evalúa el desempeño en sectores donde los tres niveles de gobierno tienen responsabilidad y donde el rol de los gobiernos locales era muy acotado antes de la LPP.

Se utilizan tres indicadores de desempeño (resultados) correspondientes a los sectores Salud, Educación e Infraestructura. En salud: mortalidad infantil, mortalidad materna y esperanza de vida; en Educación: inversa de la tasa de analfabetismo y años promedio de estudio; en vivienda y servicios urbanos: porcentajes de viviendas con conexión de energía eléctrica, con conexión de agua y con descarga a alcantarillados. Dentro de cada sector se utiliza la misma ponderación para cada indicador parcial (en salud y vivienda y servicios urbanos, un tercio cada uno; en educación, un medio cada uno). En todos los casos se trata de mediciones del outcome ${ }^{14}$.

Para construir el indicador sintético de desempeño se utilizan dos ponderaciones: por igual cada uno de los sectores o según la importancia en el gasto de los tres sectores. Los resultados se presentan en la Tabla 2.

Los ocho indicadores y los tres sectoriales muestran importantes crecimientos entre 1992 y 2001 y entre 2001 y 2012. El indicador sintético en 2012 es aproximadamente el doble del de 1992 (índices 187,8 y 210,5 según las ponderaciones en 2012, base 100 en 1992). Si estos resultados se asocian directamente con las políticas implementadas en el período, en especial con las políticas de descentralización, el impacto ha sido positivo. La mejora ha sido mayor entre 2001 y 2012 (alrededor de 60\%) que entre 1992 y 2001 (alrededor de 30\%). El desempeño ha mejorado a una tasa anual acumulativa del $3,8 \%$ entre puntas y del $2,6 \%$ (entre 1992 y 2001) y 4,6\% (entre 2001 y 2012), que puede adjudicarse a la maduración del proceso de descentralización.

Como se expresó antes, para calcular el impacto económico-social de una política o acción gubernamental es necesario considerar también el lado de los costos, que se miden con el gasto público en cada sector en términos del producto interno bruto. En la Tabla 3 se presenta la información utilizando promedios rezagados para contemplar que la diferencia entre el momento del gasto y la producción del beneficio; el promedio

14 Es factible señalar que los indicadores que se calculan son proxies de las dimensiones que se pretenden medir. La disponibilidad de información es un condicionante al momento de construir indicadores representativos. En línea con lo planteado por Aled ab Iorwerth (2006), los indicadores de desempeño no son una medida perfecta del outcome, pero podrían ser proxies razonables. En tal sentido, vale la reflexión de Caplan (1998): it is better to measure the right thing approximately than the wrong thing precisely. 


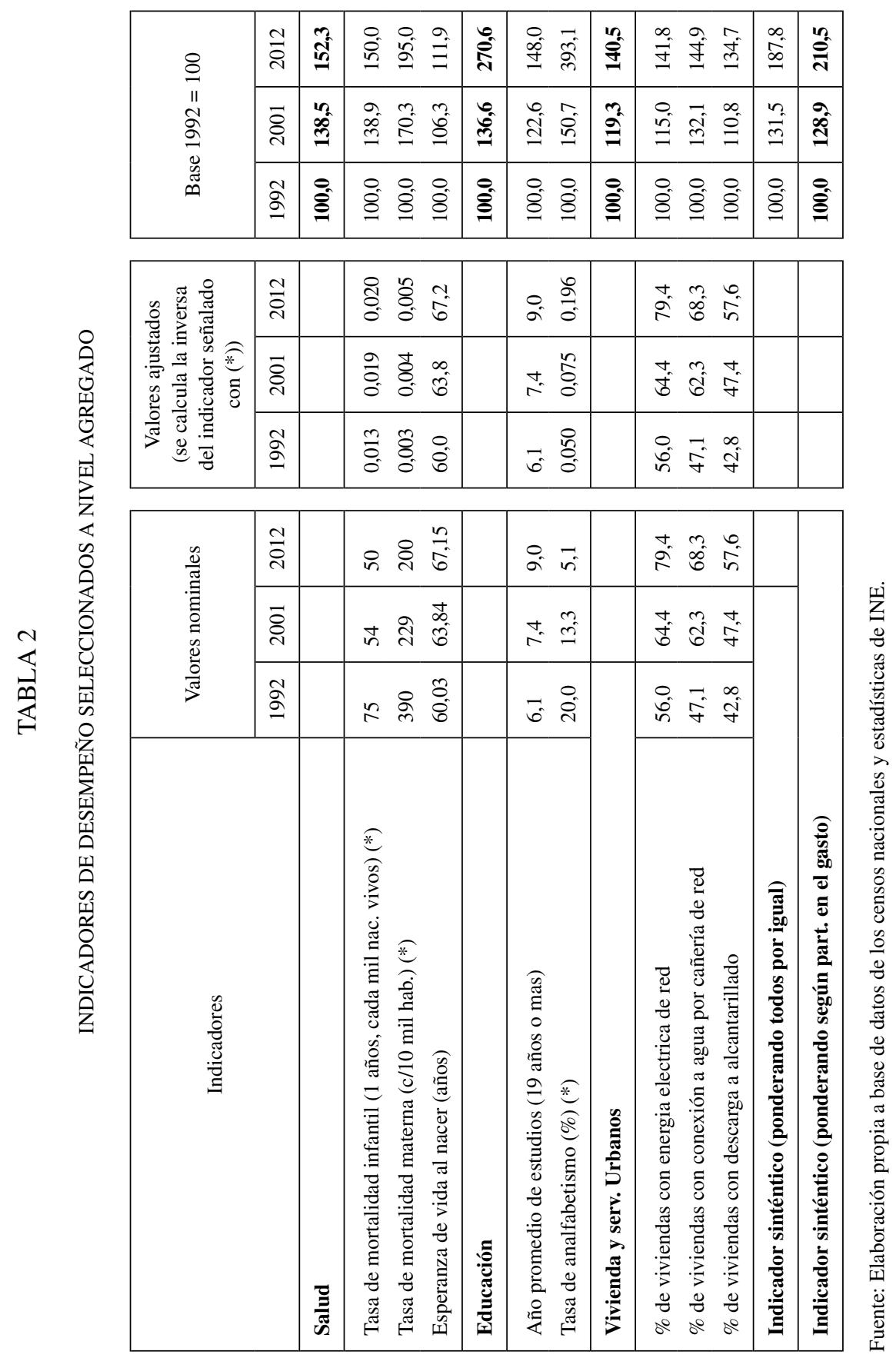




\section{TABLA 3}

GASTO PUBLICO CONSOLIDADO DE LOS TRES SECTORES SELECCIONADOS. EN \% DEL PIB

\begin{tabular}{|c|c|c|c|}
\hline \multirow{2}{*}{ Gasto social consolidado } & $\begin{array}{l}\text { Prom. } \\
90-92\end{array}$ & $\begin{array}{l}\text { Prom. } \\
95-99\end{array}$ & $\begin{array}{c}\text { Prom. } \\
\text { 2006-2010 }\end{array}$ \\
\hline & \multicolumn{3}{|c|}{ En $\%$ del PIB } \\
\hline Salud & 1,7 & 1,3 & 2,1 \\
\hline Educación & 3,7 & 4,1 & 5,3 \\
\hline Vivienda y servicios básicos & 0,6 & 1,2 & 1,0 \\
\hline Total sectores seleccionados & $\mathbf{5 , 9}$ & 6,6 & 8,3 \\
\hline
\end{tabular}

\begin{tabular}{|c|c|c|}
\hline $\begin{array}{l}\text { Prom. } \\
90-92\end{array}$ & $\begin{array}{l}\text { Prom. } \\
95-99\end{array}$ & $\begin{array}{c}\text { Prom. } \\
\text { 2006-2010 }\end{array}$ \\
\hline \multicolumn{3}{|c|}{ Base $1992=100$} \\
\hline 100,0 & 75,8 & 124,3 \\
\hline 100,0 & 111,8 & 143,9 \\
\hline 100,0 & 208,9 & 174,5 \\
\hline 100,0 & 111,1 & 141,3 \\
\hline
\end{tabular}

Nota: El gasto en salud es neto de seguridad social y el gasto en educación no incluye universidades. Fuente: Elaboración propia a base de datos de UDAPE.

es útil también para compensar fluctuaciones anuales. Los resultados indican que, en general, los gastos aumentaron en los tres sectores (para el total de los tres sectores el $11,1 \%$ entre $1990-92$ y $1995-99$ y $41,3 \%$ entre $1990-92$ y 2006-2010).

La eficiencia se mide comparando los beneficios y los gastos. Los resultados se muestran en la Tabla 4. Entre puntas ha mejorado la eficiencia en los sectores salud $(22,5 \%)$, educación $\left(88 \%{ }^{15}\right)$ y, en sentido contrario, se observa un decrecimiento en vivienda y servicios urbanos $(-19,5 \%)$. El indicador sintético muestra mejoras entre el $32,9 \%$ y $48,9 \%$, según el ponderador ${ }^{16}$. La diferencia en la evolución de la eficiencia entre los sectores puede asignarse, al menos parcialmente, a las características de la producción. Hay mejoras en salud que pueden obtenerse en forma relativamente rápida para algunas poblaciones (p.ej. en mortalidad infantil y materna), aunque luego aumenten las dificultades al agregarse poblaciones con necesidades más complejas. En cambio, en educación, la obtención de resultados demanda más tiempo (hasta que se completen años de educación). En forma similar, lleva más tiempo obtener resultados en vivienda y servicios urbanos.

15 Una forma de interpretar este resultado es la siguiente: la eficiencia en educación aumentó $88 \%$ debido a los aumentos del 170,6\% en el desempeño y del 43,9\% en el gasto en términos del PIB. La elasticidad de arco desempeño-gasto es igual a 3,9 indicando que la eficiencia aumenta cuando aumenta el gasto. La misma interpretación para los otros sectores y para los indicadores sintéticos.

16 Una forma alternativa es considerar el costo medio de los resultados (indicador sintético). 


\section{TABLA 4}

\section{INDICADORES DE EFICIENCIA: \\ RELACION ENTRE INDICADORES DE DESEMPEÑO Y DE GASTO PUBLICO EN LOS TRES SECTORES}

\begin{tabular}{|l|c|c|c|}
\hline \multicolumn{1}{|c|}{ Relaciones de indicadores } & 1992 & 2001 & 2012 \\
\hline Indicador salud /Gasto total en salud & 100,0 & 182,6 & 122,5 \\
Indicador educación / Gasto total en educación & 100,0 & 122,2 & 188,0 \\
Indicador vivienda y ss. urbanos/ Gasto total en viv. y ss. urb. & 100,0 & 57,1 & 80,5 \\
Indicador sintético / Gasto (1) & 100,0 & 118,3 & 132,9 \\
Indicador sintético / Gasto (2) & 100,0 & 116,1 & 148,9 \\
\hline (GM+GD)/ GT (sin emp.) (base 1992=100) & 100,0 & 158,5 & 203,2 \\
GM / (GM+GD) (base 1992=100) & 100,0 & 272,2 & 447,1 \\
\hline
\end{tabular}

(1) Ponderando todos los sectores iguales.

(2) Ponderaciones en función de la participación relativa de cada sector en el gasto.

Referencias: GM: gobiernos municipales; GD: gobiernos departamentales; GC: gobierno central. El gobierno general comprende al sector público no financiero sin las empresas públicas.

Los coeficientes de descentralización en las dos últimas filas de la Tabla 4 sugieren, preliminarmente, que existe asociación positiva a nivel global entre la descentralización fiscal y la eficiencia.

\section{Desempeño, gastos y eficiencia por departamentos (departamento y sus municipalidades)}

En esta subsección se desagregan los indicadores a nivel de cada uno de los nueve departamentos. En la Tabla 5 se calculan las diferencias de desempeño entre los departamentos para distintos momentos; los valores superiores (inferiores) a 100 indican que el desempeño es mayor (menor) en ese departamento con relación al promedio. Las diferencias interdepartamentales -medidas con el coeficiente de variación- disminuyen a lo largo del tiempo en los sectores salud y vivienda y servicios urbanos y aumentan en educación. Para los indicadores sintéticos las diferencias disminuyen.

En la Tabla 6 se presenta la evolución del desempeño, para cada departamento y para el promedio, entre 1992 (base) y los años 2001 y 2012. El desempeño mejoró en todos los departamentos. La mejora -ponderando cada función según su participación en el gasto- fue del 112,7\% a nivel de todo el país entre 1992 y 2012. En ocho departamentos la mejora fue relativamente similar a la agregada para el país. Pando se destaca por las mejoras observadas del orden del $267,4 \%$, versus el 


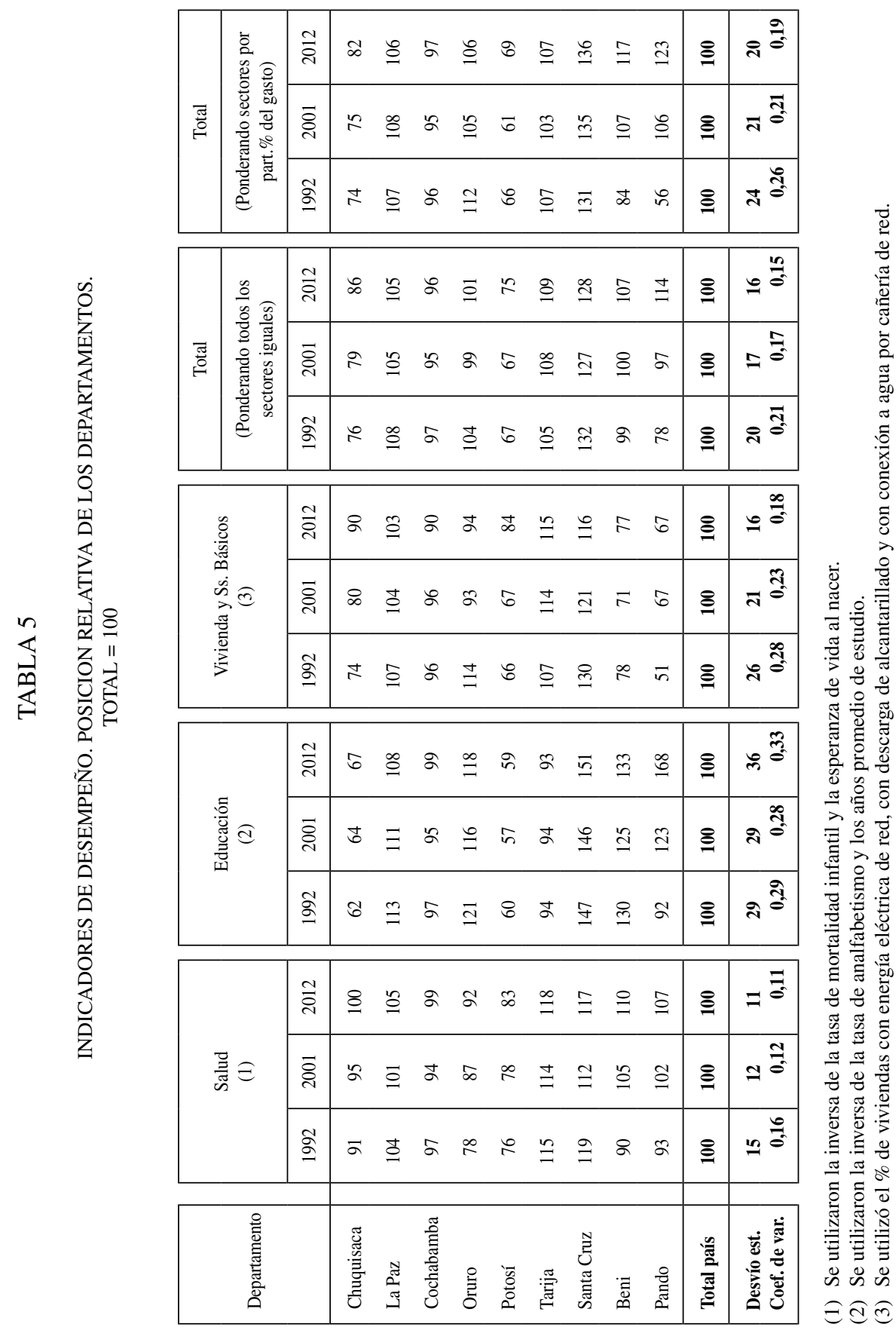




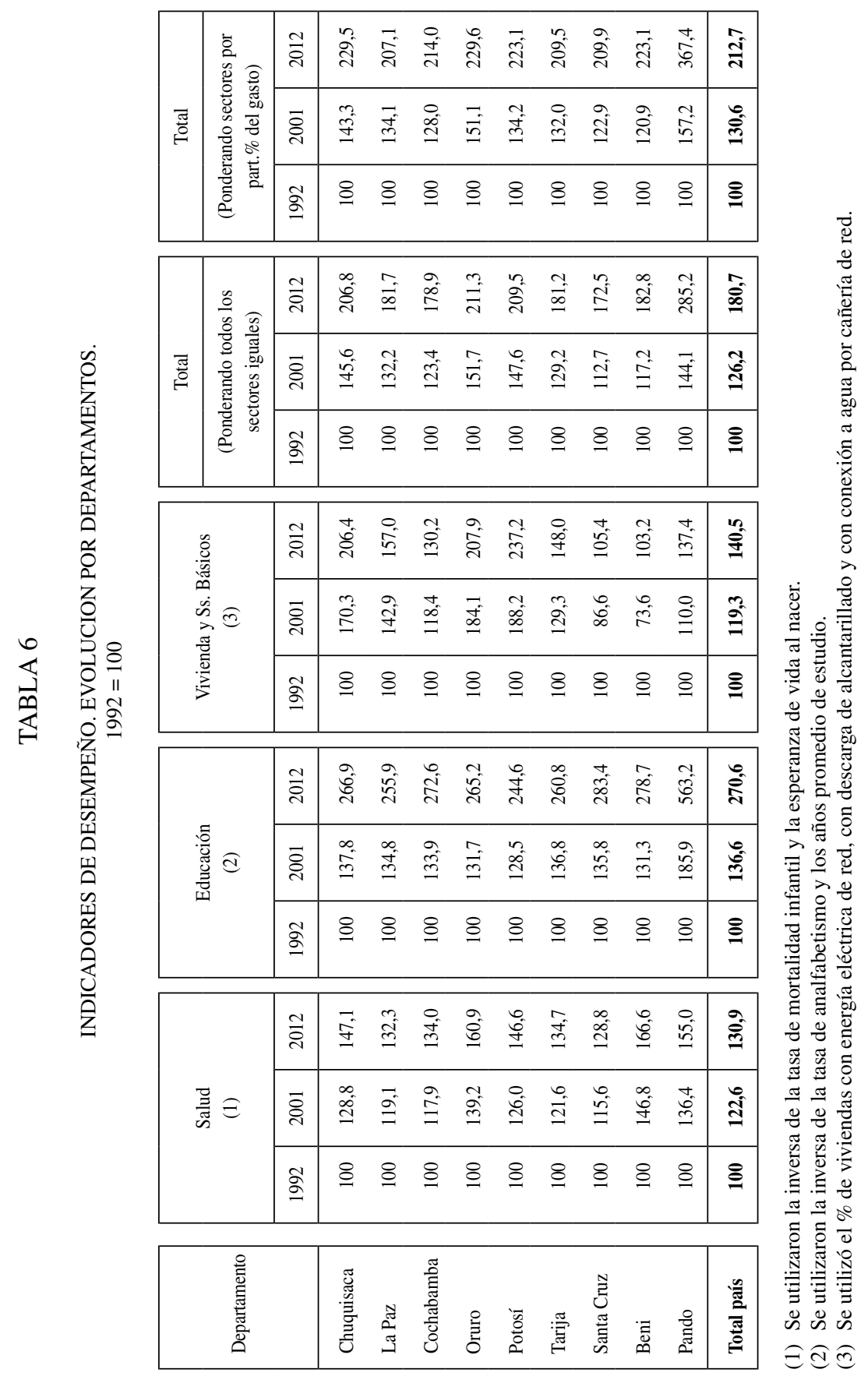


$112,7 \%$ del promedio. Resultados similares se obtienen si se ponderan por igual los tres sectores.

Esta evolución similar se verifica pese a que en el año base las diferencias de desempeño por departamentos eran significativas. En la Figura 2 se muestra la relación entre la posición relativa de los departamentos en el año base 1992 y la tasa de crecimiento del desempeño observado en 2012 (ponderando por igual a todos los indicadores). Los departamentos con desempeño por debajo del promedio en 1992 son los que muestran, en general, mayor tasa de crecimiento entre 1992 y 2012 (principalmente Pando, Chuquisaca y Potosí). Por el contrario, el departamento de Santa Cruz, que inicialmente presentaba la mejor posición relativa, exhibe la menor tasa de crecimiento en el indicador agregado de desempeño. Hay un proceso de catch-up o convergencia sugerido por la relación negativa entre las dos variables. Este resultado se puede explicar por rendimientos decrecientes a escala. Es esperable que en aquellos departamentos con mayor grado de desarrollo sea más costoso incrementar marginalmente su desempeño.

FIGURA 2

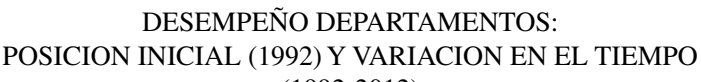

(1992-2012)

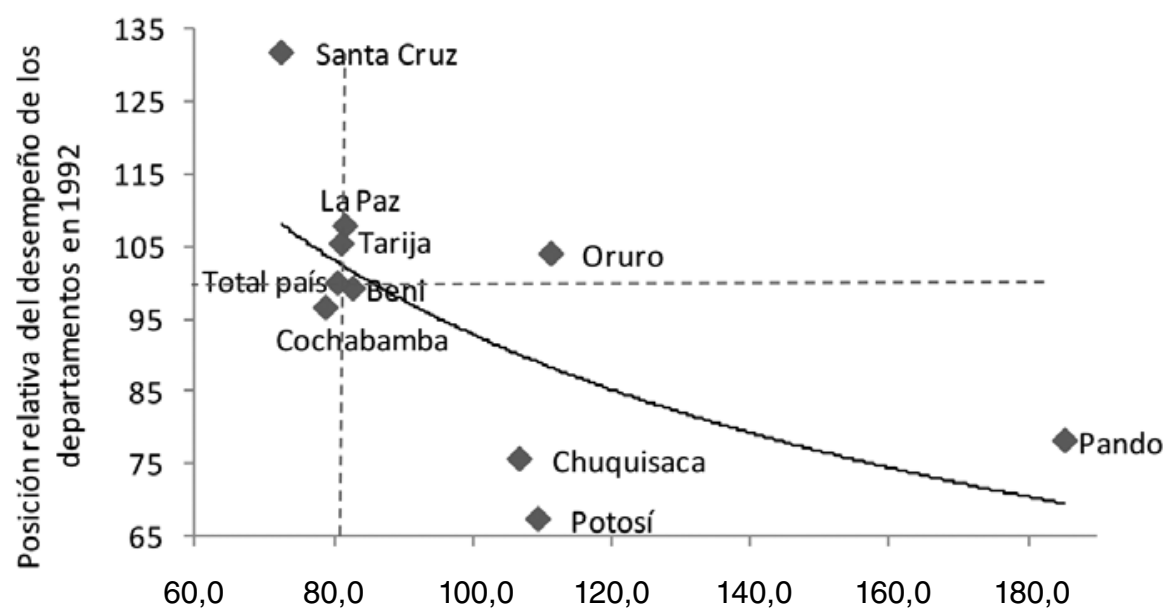

Tasa de crecimiento del desempeño por departamento (1992-2012) 
En las dos tablas siguientes se incluye la información del gasto público en términos del PBG, de los tres niveles de gobierno, para cada uno de los tres sectores y el total. La estructura relativa del gasto se incluye en la Tabla 7 y la evolución en la Tabla 8.

Hay importantes diferencias en la posición relativa de los departamentos en los tres momentos de tiempo analizados. De los cuatro departamentos con gasto superior al promedio en 1990-92, tres perdieron posición relativa (La Paz, Oruro y Potosí); de los cuatro que estaban por debajo del promedio, tres aumentaron su posición relativa (Cochabamba, Santa Cruz y Pando) y uno la disminuyó (Tarija); Chuquisaca, con gasto igual al promedio en 1990-92, aumentó su participación.

La evolución del gasto (Tabla 8) muestra importantes incrementos entre 199092 y $1995-99(11 \%)$ y entre $1990-92$ y 2006-2010 (41\%). Solo dos departamentos registran disminución entre las dos últimas observaciones (Tarija y Potosí). En el caso más relevante (Tarija) se observa un importante crecimiento de su producto bruto geográfico, impulsado por el aumento de precios de los hidrocarburos que explican la disminución.

La Figura 3 relaciona la posición inicial de los departamentos en el gasto público social con la tasa de crecimiento. La relación observada es negativa, indicando que, en general, los departamentos con menor posición relativa inicial son los que muestran mayores tasas de crecimiento del gasto.

Los indicadores de eficiencia a nivel de departamentos se presentan en las Tablas 9 (posición relativa de cada departamento) y 10 (evolución).

En la Figura 4 se presenta la posición relativa inicial (1992) y la tasa de variación de la eficiencia por departamentos.

Con ponderación de cada sector igualitario, se observa que hay aumentos en la eficiencia entre 1992 y 2012, salvo ligera disminución en Chuquisaca y más importante en Beni, que disminuye 20,8\% ${ }^{17}$. Departamentos que parten de una situación similar en cuanto a eficiencia muestran tasas de variación muy distintas. Con ponderaciones según el tamaño del gasto la única disminución muy leve (1\%) se verifica en Beni.

Si bien el número de observaciones y la disponibilidad de datos no permiten realizar estimaciones estadísticas robustas, se calculó la relación logarítmica entre la posición inicial y tasa de crecimiento en el tiempo de las variables. Los resultados se muestran en la Tabla 11. El signo negativo indica que los departamentos con mejor posición inicial exhiben una menor tasa de crecimiento de la eficiencia.

17 Los hechos que se destacan corresponden al indicador de eficiencia para el total de sectores, ponderándolos a todos por igual. Si se toma para el análisis los indicadores que ponderan a todos los sectores en función de su participación en el gasto total, se observan diferentes valores. En el caso de Beni, la caída en la eficiencia estaría en el orden del $1 \%$. 


\begin{tabular}{|c|c|c|c|c|c|c|c|c|c|c|c|c|c|}
\hline & 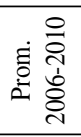 & $\begin{array}{l}\text { N } \\
\text { o } \\
\text { d }\end{array}$ & $\stackrel{\infty}{\alpha}$ & $\stackrel{\text { I }}{\Xi}$ & $\ddot{8}$ & $\begin{array}{l}\infty \\
\stackrel{+}{ \pm} \\
=\end{array}$ & $\vec{n}$ & $\vec{\infty}$ & $\stackrel{\circ}{\Xi}$ & $\begin{array}{l}\infty \\
\dot{y} \\
\dot{y}\end{array}$ & $\Xi$ & ల్ల & $\stackrel{\infty}{2}$ \\
\hline స్్ㅇ & 离 & $\begin{array}{l}0 \\
\frac{\infty}{\infty}\end{array}$ & $\stackrel{\mathscr{I}}{ \pm}$ & $\begin{array}{l}0 \\
\text { ลa }\end{array}$ & $\stackrel{\circ}{\stackrel{\oplus}{=}}$ & $\begin{array}{l}\forall \\
\infty \\
\infty\end{array}$ & 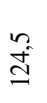 & ชै & 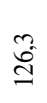 & $\stackrel{2}{n}$ & $\S$ & లి & న్. \\
\hline & 离 & $\stackrel{0}{8}$ & $\overrightarrow{\hat{\sigma}}$ & $\begin{array}{l}0 \\
\text { ḋ }\end{array}$ & $\overline{8}$ & $\stackrel{\infty}{\stackrel{\infty}{I}}$ & $\begin{array}{l}\stackrel{0}{\infty} \\
\dot{\infty}\end{array}$ & $\stackrel{0}{\dot{\infty}}$ & $\begin{array}{l}0 \\
8\end{array}$ & $\begin{array}{l}\infty \\
+ \\
+\end{array}$ & 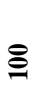 & సి & స్ \\
\hline
\end{tabular}

\begin{tabular}{|c|c|c|c|c|c|c|c|c|c|c|c|c|c|}
\hline \multirow{3}{*}{ 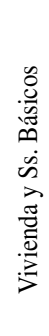 } & 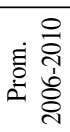 & $\overrightarrow{\widetilde{\Xi}}$ & $\overrightarrow{\mathrm{g}}$ & $\hat{\ddot{g}}$ & $\stackrel{\circ}{a}$ & ָิ & $\stackrel{+}{\stackrel{f}{q}}$ & นู & $\stackrel{m}{ \pm}$ & $\hat{a}$ & $\S$ & లి & ल্. \\
\hline & 홀 & बे & $\stackrel{0}{\stackrel{\Xi}{=}}$ & $\begin{array}{l}\infty \\
\varrho \\
\varrho\end{array}$ & $\frac{\pi}{\sigma}$ & $\begin{array}{l}\infty \\
\stackrel{\infty}{\infty}\end{array}$ & $\begin{array}{l}n \\
\ddot{8} \\
n\end{array}$ & 点 & $\frac{n}{ \pm}$ & $\frac{2}{\tilde{I}}$ & $\S$ & $F$ & F \\
\hline & غ்̇ & $\stackrel{0}{8}$ & $\stackrel{+}{5}$ & $\bar{\varnothing}$ & $\overrightarrow{0}$ & $\begin{array}{l}6 \\
\infty \\
\triangle\end{array}$ & भू. & $\stackrel{m}{\infty}$ & ले & $\frac{\sim}{\infty}$ & $\Xi$ & లా & ल् \\
\hline
\end{tabular}

\begin{tabular}{|c|c|c|c|c|c|c|c|c|c|c|c|c|c|}
\hline \multirow{3}{*}{ 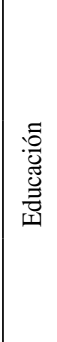 } & 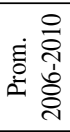 & 产 & शे & $\stackrel{n}{\varrho}$ & $\begin{array}{l}\infty \\
\infty \\
\infty\end{array}$ & $\stackrel{m}{\Xi}$ & $\hat{q}$ & $\hat{8}$ & $\stackrel{\infty}{\stackrel{\infty}{\Xi}}$ & $\frac{1}{0}$ & $\Xi$ & 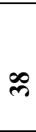 & 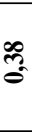 \\
\hline & 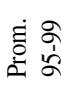 & 志 & $\stackrel{\stackrel{+}{\Xi}}{\Xi}$ & ஃু & @i & $\overrightarrow{\tilde{\lambda}}$ & $\stackrel{\circ}{\Xi}$ & है & $\stackrel{\infty}{\tilde{\Omega}}$ & $\stackrel{\vec{g}}{-}$ & $\Xi$ & f & ક̊ \\
\hline & 离 & $\begin{array}{l}\text { I } \\
\text { ḋ }\end{array}$ & $\begin{array}{l}1 \\
\infty \\
0\end{array}$ & $\hat{\sigma}$ & $\stackrel{\text { I }}{\stackrel{ \pm}{=}}$ & $\stackrel{\infty}{\stackrel{0}{\Omega}}$ & $\begin{array}{l}+ \\
\infty \\
\infty\end{array}$ & $\vec{\infty}$ & $\vec{g}$ & $\hat{े}$ & \& & సి & సે \\
\hline
\end{tabular}

wite

\begin{tabular}{|c|c|c|c|c|c|c|c|c|c|c|c|c|c|}
\hline \multirow{3}{*}{ 蚫 } & 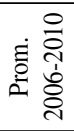 & ๙ิ & 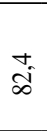 & $\vec{g}$ & $\begin{array}{l}\infty \\
\sigma \\
\sigma\end{array}$ & $\overline{\vec{I}}$ & $\frac{\infty}{\sigma}$ & $n$ & $\frac{\stackrel{m}{+}}{\sim}$ & $\hat{\bar{N}}$ & ఏ్ & bे & \\
\hline & 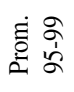 & 气ิ & $\stackrel{0}{i}$ & ci & $\stackrel{+}{i}$ & $\stackrel{0}{\circ}$ & $\stackrel{\infty}{\stackrel{\infty}{\Xi}}$ & हे & $\begin{array}{l}0 \\
\dot{0} \\
\infty\end{array}$ & ڤे & ఏ & in & "2: \\
\hline & 离 & $\begin{array}{l}0 \\
\stackrel{0}{0}\end{array}$ & $\stackrel{+}{\stackrel{0}{\sigma}}$ & $\bar{\delta}$ & $\vec{\Xi}$ & $\begin{array}{l}0^{\circ} \\
\subseteq\end{array}$ & $\begin{array}{l}n \\
\text { aे }\end{array}$ & $\stackrel{?}{\infty}$ & હे & $\frac{N}{\infty}$ & 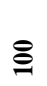 & ల్ల & \\
\hline
\end{tabular}

\begin{tabular}{|c|c|c|c|c|c|c|c|c|c|c|}
\hline 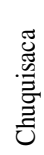 & 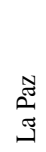 & 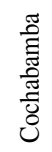 & 总 & 过 & : & 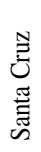 & 㐫 & $\begin{array}{l}\text { : } \\
\text { : } \\
\text { : }\end{array}$ & & $\begin{array}{l}\dot{0} \\
\stackrel{0}{0} \\
\stackrel{0}{0} \\
\stackrel{0}{0}\end{array}$ \\
\hline
\end{tabular}




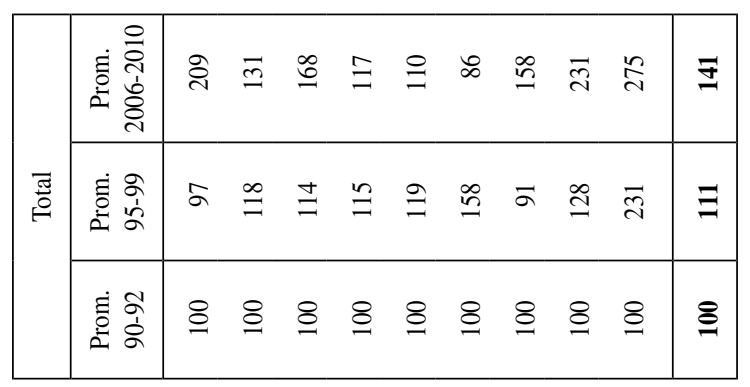

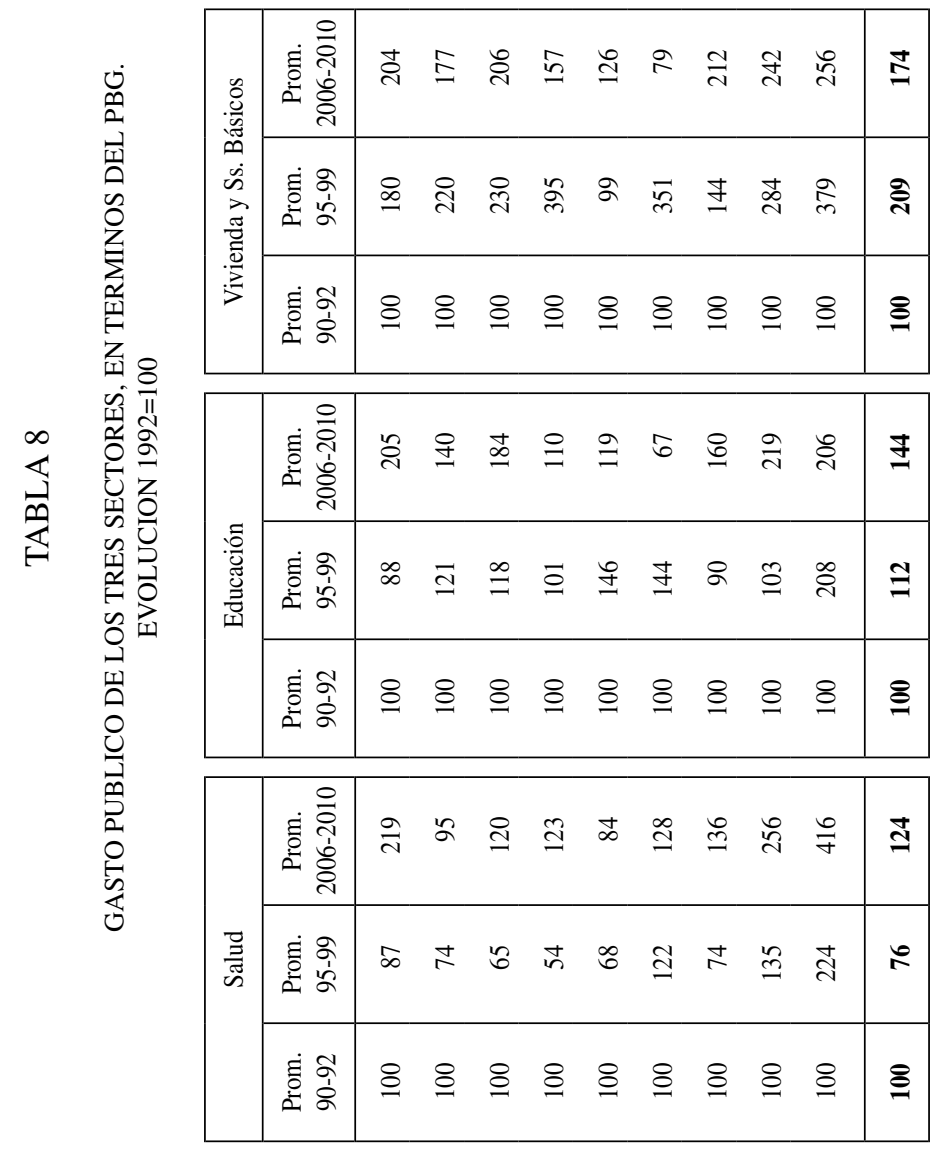

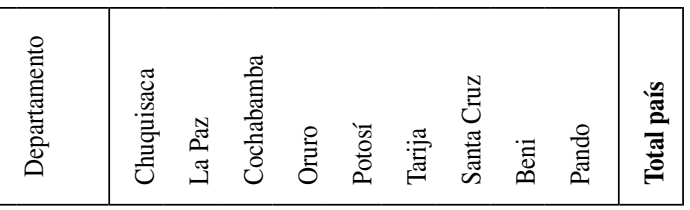




\section{FIGURA 3}

GASTO SUBNACIONAL POR DEPARTAMENTOS:

POSICION INICIAL (1992) Y VARIACION EN EL TIEMPO (1992-2012)

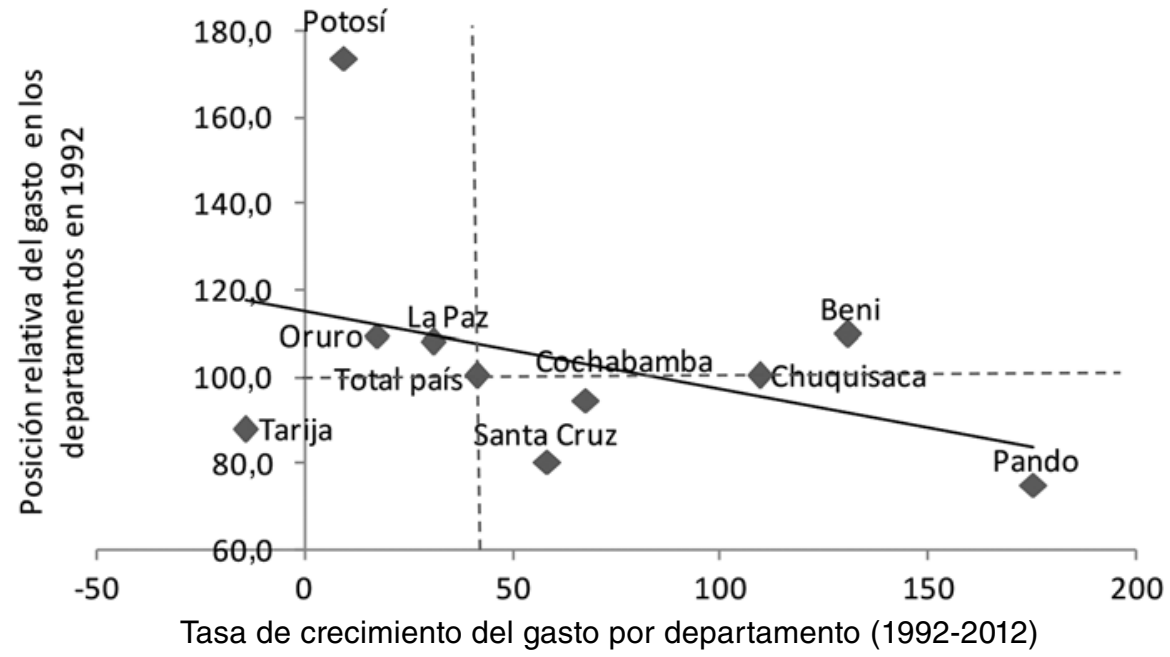

FIGURA 4

EFICIENCIA (RELACION DESEMPEÑO/GASTO SUBNACIONAL) POR DEPARTAMENTOS: POSICION INICIAL (1992) Y VARIACION EN EL TIEMPO (1992-2012)

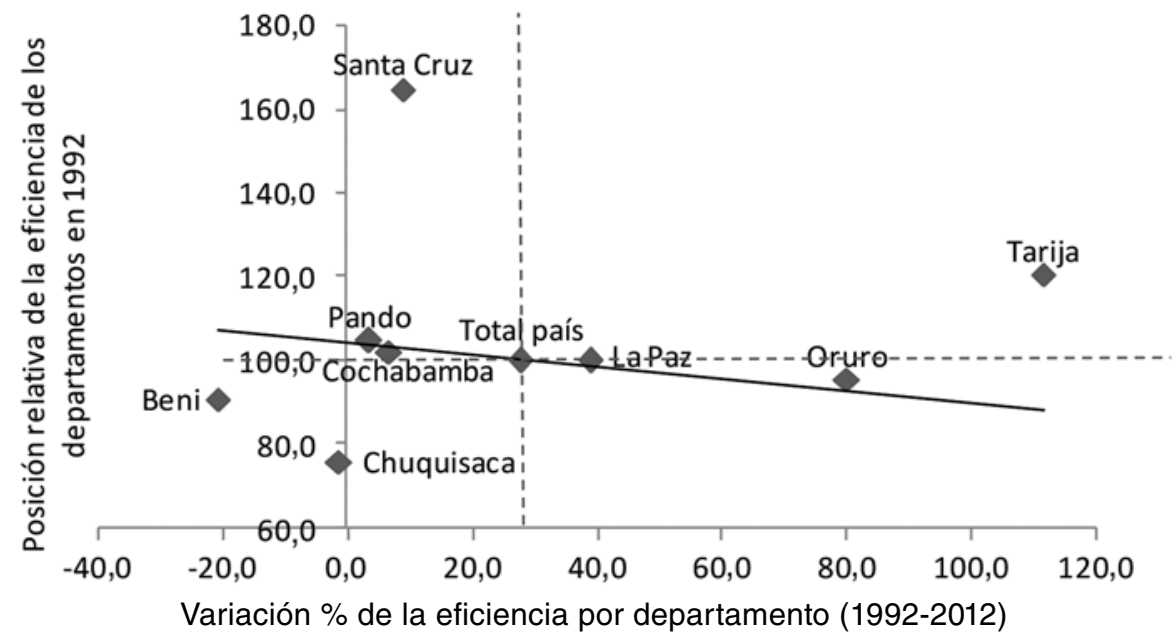




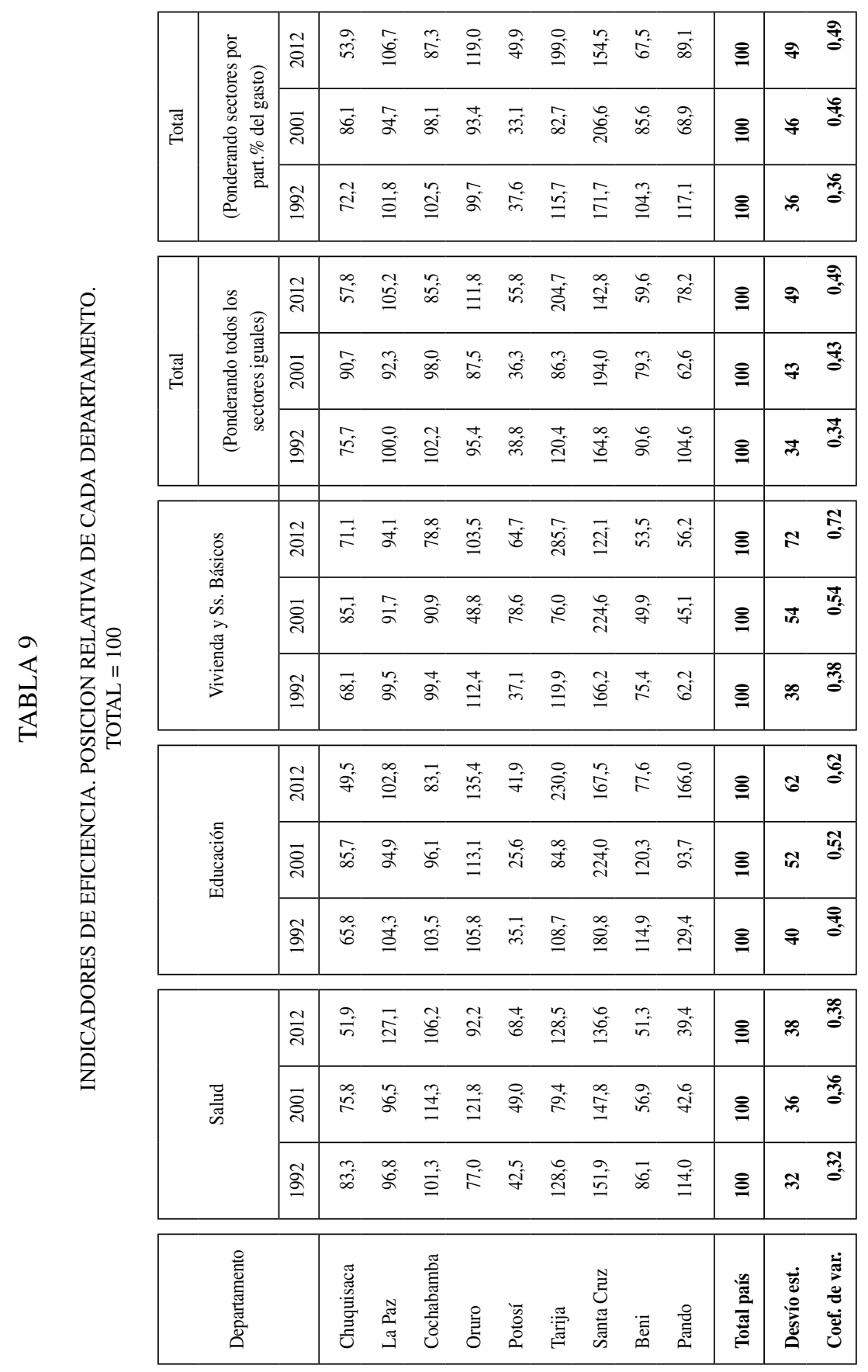




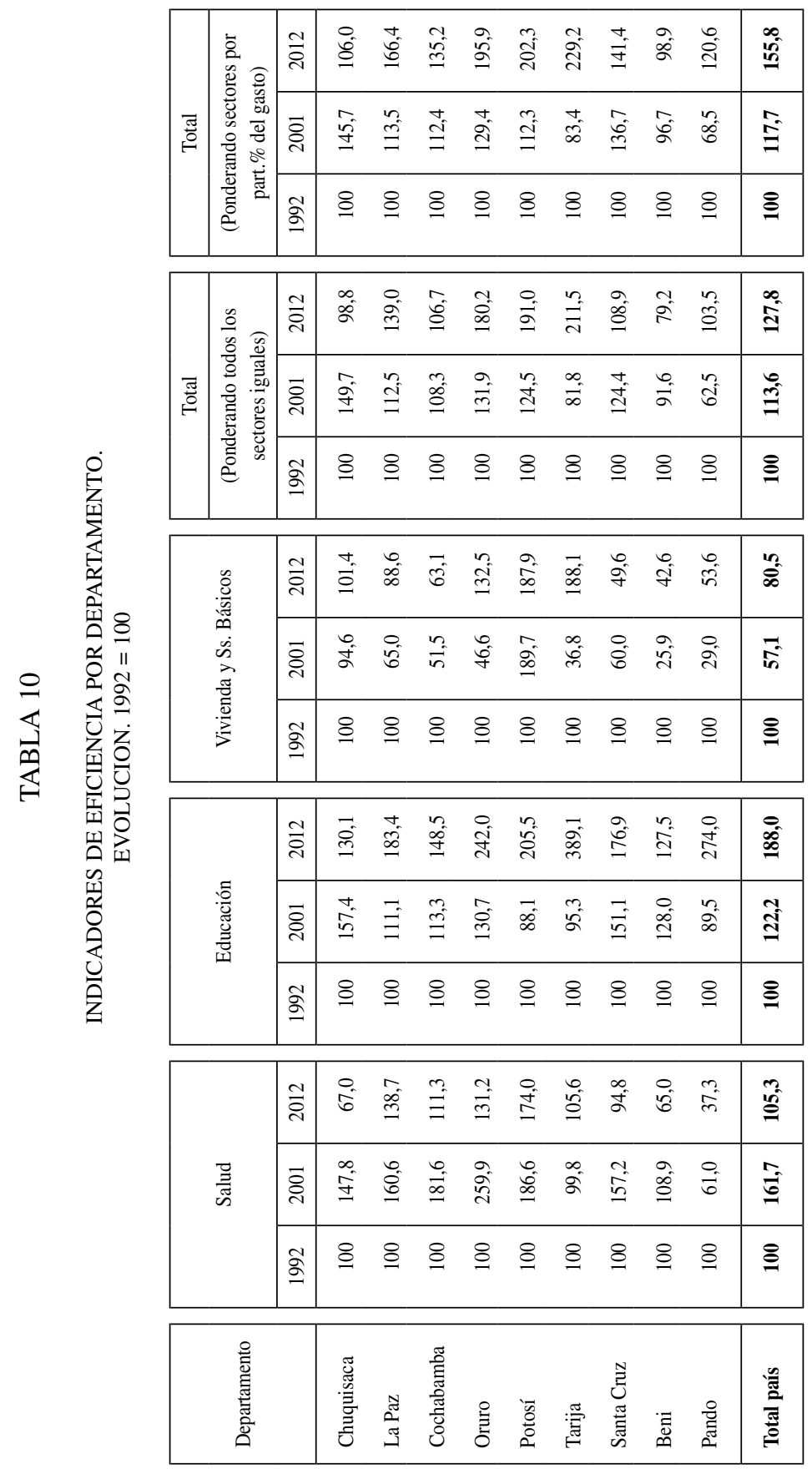




\section{TABLA 11}

\section{RELACION ENTRE CRECIMIENTO 1992-2001 Y POSICION INICIAL DE LOS DEPARTAMENTOS \\ (Para desempeño, gasto y eficiencia)}

\begin{tabular}{|l|c|c|c|}
\hline Variable & Elasticidad & t test & P-value \\
\hline Desempeño & $-0,94$ & $-2,52$ & 0,036 \\
Gasto & $-2,99$ & $-5,87$ & 0,001 \\
Eficiencia & $-1,38$ & $-3,15$ & 0,02 \\
\hline
\end{tabular}

Nota: Se calcularon regresiones MCO con las variables en logaritmo.

Variable endógena: variación en el tiempo.

Variable exógena: posición relativa inicial.

\section{DISCUSION Y CONCLUSIONES}

La eficiencia es una de las dimensiones a considerar cuando se estudia la calidad del sector público. La eficiencia se define como la relación entre los resultados (outcomes) de las acciones gubernamentales y sus costos. La medición del desempeño se ha centrado en el lado de los insumos o de los outputs en forma separada. Mucha de la bibliografía aplicada reciente, que estudia el impacto de las políticas públicas y las acciones gubernamentales, se limita a los resultados. De esa forma se mide el beneficio de una política sin considerar los costos. Es un enfoque parcial, útil como primer paso, pero que tomado aisladamente pude llevar a conclusiones erróneas: una política puede tener un beneficio positivo pero con costos mayores, de modo que el beneficio neto sea negativo. Si solo se mira el lado del beneficio puede recomendarse la expansión de esas actividades que son ineficientes desde el punto de vista económico.

Las cuantificaciones de este trabajo revelan importantes mejoras en el desempeño de Bolivia en tres sectores: educación, salud, y vivienda y servicios urbanos. A nivel agregado de todo el país la mejor se ubica, en el período 1992-2012, entre 87,8\% y $110 \%$ según los ponderadores (Tabla 2). Entre los mismos años, el desempeño mejora en todos los departamentos (Tabla 5).

El desempeño, medido vía la mejora en la provisión de los servicios, es parcial. Es necesario agregar el costo de las políticas y contemplar la eficiencia de las prestaciones. Con esa finalidad se cuantificó el gasto correspondiente a cada uno de los sectores. Se consideró una medida relativa del gasto, en términos del PIB. A nivel agregado (Tabla 3) el gasto así medido aumentó $11 \%$ entre 1990-92 y 1995-99 y 41\% entre 1990-92 y 2006-2010. A nivel de departamentos (Tabla 7) también aumentó. Entre 1990-92 y 2006-2010 solo disminuyó (14\%) en Tarija, debido al notable crecimiento de su PBG consecuencia del incremento en el precio de los hidrocarburos. 
La relación entre el desempeño y el gasto da la medida de eficiencia que se ha utilizado en este trabajo. A nivel agregado, los resultados se muestran en la Tabla 4. Entre puntas la eficiencia ha mejorado en los sectores salud $(22,5 \%)$, educación $(88 \%) \mathrm{y}$, en sentido contrario, se observa un decrecimiento en vivienda y servicios urbanos (-19,5\%). El indicador sintético muestra mejoras entre el 32,9\% y 48,9\%, según el ponderador. La diferencia en la evolución de la eficiencia entre los sectores se puede asignar, al menos parcialmente, a las características de la producción. A nivel de departamentos la eficiencia es muy diferente y también lo es su evolución. En particular se debe destacar que departamentos con situación muy similar en el punto inicial exhiben tasas de variación muy distintas.

Una cuestión intrigante es la relación de estas medidas con el proceso de descentralización que se llevó a cabo en el período ${ }^{18}$. Los desarrollos anteriores sugieren, al menos preliminarmente, que existe asociación positiva entre la descentralización fiscal y las medidas de desempeño. Esta conclusión preliminar coincide con Faguet (2004) que compara la provisión central con la descentralizada de la inversión en varios sectores. Su conclusión es que la inversión estuvo concentrada en las capitales de los departamentos antes de la Ley de Participación Popular y luego se distribuyó más igualitariamente entre los municipios. La ley cambió drásticamente el patrón de distribución territorial de la inversión, y la inversión en los distintos sectores respondió a necesidades (determinantes). Por ejemplo, las municipalidades con mayor tasa de analfabetismo son las que aumentaron más la inversión en educación, etc. Faguet se concentra en la distribución de la inversión (que es una medida del lado del gasto), en tanto que el trabajo presente enfatiza el efecto del gasto sobre desempeño-gasto-eficiencia.

Burki y otros (1999) consideran que un rasgo a destacar de la descentralización en Bolivia (distinto a la descentralización en cualquier otro país de América Latina y el Caribe) es el rol de la organización de la sociedad civil en las decisiones de asignación de recursos y acciones de control a nivel local. Como resultado de ello, ha sido marcado el crecimiento de las organizaciones participativas durante los primeros años de vigencia de la Ley de Participación Popular (1994) y los ciudadanos han demostrado un alto interés en la planificación y supervisión de las inversiones locales de los gobiernos municipales. Faguet (2012), al estudiar los efectos de la descentralización a nivel municipal, asigna un rol central a diferencias en las variables político-sociales (organizaciones ciudadanas, intereses económicos y actores políticos interactuando en la toma de decisiones). Estas diferencias pueden explicar las encontradas en este trabajo a nivel de departamentos en cuanto a eficiencia.

18 Ver Tabla 12 del Anexo. 
Sin embargo, la evaluación de los efectos de la descentralización ha generado opiniones diferentes entre los autores. Mesa Gisbert concluye que la nueva Constitución Política (2009) da un paso político-social de importancia al reconocer a las naciones y pueblos indígenas originarios campesinos, pero no se observan avances significativos en el proceso de descentralización a nivel subnacional y local (ver Tabla 12 del Anexo). Según Mesa Gisbert ${ }^{19}$ : Se trata del hecho de que el Gobierno al que le tocó ejecutar el proyecto autonómico reivindicado históricamente e impulsado a partir de 2003 no contemplaba en su concepción un modelo autonómico global, ya que por su naturaleza creía en el centralismo (inspirado en el "centralismo democrático" de origen marxista). Para tratar de entender esta visión centralista del gobierno se puede pensar que los gobiernos locales se encuentran en desarrollo, muchos de ellos con capacidades fiscales incipientes. Estos tomaron impulso recién a partir de la Ley de Participación Popular (1994) y a partir de entonces es que empezaron paulatinamente a desarrollar sus capacidades gerenciales. Mientras tanto, el gobierno central debe tener una presencia más marcada. Inchauste $(2009)^{20}$ concluye que el objetivo de equidad de la descentralización no ha sido logrado. No encuentra evidencia de que el incremento del gasto por municipalidades haya tenido impacto positivo en indicadores sociales. Adjudica este resultado a que el gasto de todos los niveles de gobierno ha sido pobremente focalizado, mala gestión y mala asignación de responsabilidades entre el gobierno central y los gobiernos subnacionales. Ahmad y Brosio (2009) señalan que no se puede afirmar que las transferencias con asignación específica representen las preferencias de las comunidades. La reorientación de los fondos es el resultado de las actuaciones del gobierno central y no de lo que hagan las administraciones locales. Ahmad y García Escribano (2010) resaltan que "la asignación de responsabilidades de gasto que ha predominado en Bolivia durante la mayor parte de la década actual es evidente, y que la estructura de superposiciones imperante deja muy pocas responsabilidades a los municipios en materia de atención de salud y educación", "En el caso de la educación básica, los gobiernos locales se ocupan apenas de algunas operaciones relacionadas con el mantenimiento y la reparación de instalaciones, mientras que el gobierno central se encarga de pagarles a los maestros, a los departamentos por contratarlos y a los municipios por verificar las horas trabajadas. De ese modo, es difícil saber qué nivel de gobierno es responsable por la educación primaria...".

Estas opiniones opuestas pueden compatibilizarse con avances en la investigación. Pero algunos hechos deben tenerse en cuenta. En primer lugar, como surge de los trabajos de Faguet y el Banco Mundial, la participación ciudadana se incrementó notablemente como consecuencia de la LPP, lo que en sí mismo es un resultado positivo. Bird y Vaillancourt 1998, p. 4) consideran que Whatever the precise outcomes of adopting a decentralized (in the sense of devolved) system of decision-making,

19 En Zuazo, Faguet y Bonifaz (2012).

20 Las estimaciones pueden tener grandes errores, como expresa la autora en la nota de pie 7 de su trabajo. 
such outcomes are presumed, from this perspective, to be satisfactory because the process itself is intrinsically desirable. Local people may make wrong decisions from the perspective of the central government or of an outside observer, but if they make them, the decision must, by definition, be assumed to be right for them. From this perspective, then, decentralization is intrinsically good because institutionalized the participation of those affected by local decisions. The results of a good process must themselves be good. En segundo lugar, La Porta et al. (1998) presentan evidencia de que la calidad del gobierno, entre países, depende de la influencia de las circunstancias históricas, capturadas por las heterogeneidades étnico-lingüísticas, orígenes legales y religión. Faguet documenta claramente que los resultados a nivel de municipalidades en Bolivia son diferentes según la organización ciudadana, los intereses económicos y los factores políticos que interactúan en la toma de decisiones. En tercer lugar, el hecho exógeno detallado en la Sección II, debido al notable incremento del precio de los hidrocarburos en la década de los 2000, modificó notablemente la distribución del financiamiento de los departamentos y municipalidades previsto en la LPP. Esta ley consagró como criterio de distribución a la población, que implica igualdad per cápita. El incremento en el precio de los hidrocarburos modificó sustancialmente la distribución, ya que los fondos provenientes del impuesto sobre los combustibles se distribuyen entre las jurisdicciones en las que están ubicados los yacimientos. El total de transferencias a gobiernos subnacionales se apartó de la igualdad per cápita: Tarija obtuvo 4,5 veces lo que recibía el promedio, Pando 4,3 veces, en tanto que en el otro extremo La Paz obtuvo 46\% menos que el promedio.

La principal conclusión de este trabajo es una presunción de existencia de relación positiva entre desempeño en los sectores salud, educación, y vivienda y servicios urbanos y descentralización. Con la mejora en el desempeño aumentó también la participación política de los ciudadanos, de modo que puede concluirse, preliminarmente, que el país se movió en uno de los intervalos positivos de la frontera del federalismo de Inman y Rubinstein $(1997)^{21}$. El aumento de la participación política no tuvo el mismo efecto en todas las jurisdicciones, como demuestra Faguet, debido a la distinta interacción de las variables que influyen en la toma de decisiones. La medida del desempeño se debe complementar con la de eficiencia. En este caso el resultado de mejoría se mantiene pero es de menor magnitud a nivel global y muestra diferencias entre los departamentos que quedan ocultos cuando se utilizan solo las medidas de desempeño.

Como en toda investigación aplicada, el trabajo tiene limitaciones que se originan, fundamentalmente, en la falta de información. Pero utilizando la información disponible se llega a resultados que pueden ser contrastados en futuras investigaciones. Resta para

21 Participación política y eficiencia son objetivos conflictivos de modo que, en general, la tasa marginal de transformación es negativa. Pero partiendo de un modelo centralizado el paso a la descentralización permite obtener ganancias en la participación popular (p. ej. mayor número de unidades de gobierno próximas a la gente, con autoridades elegidas por el voto en las urnas) y en la eficiencia (p.ej. las que surgen del teorema de la descentralización de Oates (1972). 
la agenda futura de investigación encontrar factores explicativos de las diferencias entre departamentos. Además de las variables políticas antes mencionadas se debe agregar el cambio en la situación fiscal interdepartamental por modificaciones introducidas en el financiamiento subnacional, p.ej., la filosofía central de la LPP en cuanto al reparto de fondos (igual per cápita) se modificó significativamente como consecuencia del criterio utilizado para distribuir las transferencias entre los departamentos y las municipalidades (basados en la ubicación de los yacimientos).

\section{REFERENCIAS}

AFONSO, A., L. SCHUKNECHT, and V. TANZI (2003). "Public sector efficiency: an international comparison", European Central Bank, Working Paper No 242, http://www.ecb.europa.eu/pub/pdf/ scpwps/ecbwp242.pdf.

AHMAD, E. and G. BROSIO (2009). "Does decentralization enhance service delivery and poverty reduction?". E. Elgar.

AHMAD, E. y M. GARCIA ESCRIBANO (2010): "Economía política de la descentralización y gobernabilidad", en De la Cruz, R., C. Pineda y C. Pöschl (eds., 2010), https://issuu.com/idb_publications/docs/ book_es_11998.

ALED AB IORWERTH (2006). "How to measure government productivity: a review article on Measurement of government output and productivity for the national accounts (The Atkinson Report)", International Productivity Monitor. Centre for the Study of Living Standards, vol. 13, http://www.csls.ca/ipm/13/ IPM-13-Iorwerth-e.pdf.

ATKINSON, A. (2005). "Measurement of UK government output and productivity for national accounts", Journal of the Statistical and Social Inquiry Society of Ireland, Vol. XXXIV.

BRADFORD, D.F., H.A. MALT and W.E. OATES (1969). "The rising cost of local public services: some evidence and reflexions", National Tax Journal, June.

BURKI, S., G. PERRY y W. DILLINGER (1999). "Más Allá del Centro: La Descentralización del Estado". Banco Mundial, http://documentos.bancomundial.org/curated/es/1999/07/5341845/ beyond-center-decentralizing-state-mas-alla-del-centro-la-descentralizacion-del-estado

CAPLAN, D. (1998). "Measuring the output of Non-Market Services". Economic Trends 539, October, pp. $45-49$.

DE LA CRUZ, R., C. PINEDA y C. PÖSCHL, editores (2010). La Alternativa Local. Descentralización y Desarrollo Económico, BID, https://issuu.com/idb_publications/docs/book_es_11998

FAGUET, J.P. (2012). "Gobernabilidad desde abajo en Bolivia. Una teoría del gobierno local y dos pruebas empíricas”, en Zuazo, Faguet y Bonifaz (eds., 2012), http://eprints.lse.ac.uk/45840/1/Binder1.pdf.

FAGUET, J.P. (2004). "Does decentralization increase government responsiveness to local needs. Evidence from Bolivia", Journal of Public Economics, 88 (3-4), pp. 867-893, http://are.berkeley.edu/courses/ ARE251/2004/papers/Faguet.pdf.

GUPTA, S., K. HONJO, and M. VERHOEVEN (1997). "The efficiency of government expenditures. Experiences in Africa", IMF Working Paper 97/153, https://www.imf.org/external/pubs/ft/wp/wp97153.pdf

INCHAUSTE, G. (2009). "Decentralization in Bolivia: has it made a difference?". En E. Ahmad and G. Brosio: Does decentralization enhance service delivery and poverty reduction? E. Elgar, op. cit., 2009, pp. 161-191.

INMAN, R.P. and D.L. RUBINFELD (1977). "Making sense of antitrust State-action doctrine: Balancing political participation and economic efficiency in regulatory federalism", Texas Law Review, $\mathrm{N}^{\circ} 6$.

LA PORTA, R., F. LOPEZ-DE-SILANES, A. SHLEIFERAND and R. VISHNY (1998). "The quality of government", NBER Working Paper 6727, http://www.nber.org/papers/w6727.pdf.

LOAYZA, M. (1998). "Gasto Público Social en la Década del 90", UDAPE, http://www.udape.gob.bo/ portales_html/analisiseconomico/analisis/vol17/ART03.pdf 
MESA GIBERT, C. (2012). "Bolivia: autonomías y pluralismo político. Un modelo condicionado por el horizonte indígena”. En Zuazo, Faguet y Bonifaz (eds., 2012), http://eprints.lse.ac.uk/45840/1/ Binder1.pdf

OATES, W.W. (1972). Fiscal Federalism, Harcourt Brace Jovanovich, USA.

OCDE (2015). Government at a Glance, www.oecd.org/gov/government-at-a-glance (hay otras versions de 2009, 2011 y 2013)

PAZ ARAUCO, V., G. MOLINA, W. JIMENEZ POZO y E. YAÑEZ AGUILAR (2013). "Explaining low redistributive impact in Bolivia". Commitment to Equity, Working Paper $\mathrm{N}^{\circ}$ 6, http://www. commitmentoequity.org/publications_files/CEQWPNo6\%20LowRedistImpactBolivia\%20Jan\%20 2013.pdf

PIGOU, A.C. (1947). A study in Public Finance, Macmillan \& Co., $3^{a}$ edición.

RUIZ-MIER, F. y B. GIUSSANI (1997). "El proceso de descentralización y el Financiamiento de la Salud y la Educación en Bolivia". Series de Reforma de Política $\mathrm{N}^{\circ}$ 48, Cepal, http://hdl.handle.net/11362/7380

SANCHEZ DE LOZADA, GONZALO AND FAGUET, JEAN-PAUL (2014). "Why I decentralized Bolivia". Department of International Development, The London School of Economics and Political Science, London, UK, http://eprints.lse.ac.uk/60632/.

SEEMANN, M. (2004). "The Bolivian Decentralization Process and the Role of Municipal Associations", Hamburg Institute of International Economics, Discussion Paper $\mathrm{N}^{\circ}$ 271, http://ssrn.com/abstract=540183

TANZI, V. and L. SCHUKNECHT (1997). "Reconsidering the fiscal role of government: the international perspective", American Economic Review, 87, 2, pp. 164-168.

TANZI, V. (1999). "The quality of the public sector", IMF conference on second generation reforms", https://www.imf.org/external/pubs/ft/seminar/1999/reforms/tanzi.htm

ZUAZO, M., J.P. FAGUET y G. BONIFAZ (2012). Descentralización y democracia en Bolivia, Friedrich Ebert Stiftung, La Paz, Bolivia, http://eprints.lse.ac.uk/45840/1/Binder1.pdf 


\section{ANEXO}

\section{Información fiscal}

TABLA 12

TAMAÑO Y COMPOSICIÓN DEL GASTO PÚBLICO EN BOLIVIA POR NIVELES DE GOBIERNO (DESCENTRALIZACIÓN). (1990-2012). EN MILLONES DE \$ BS

\begin{tabular}{|c|c|c|c|c|c|c|c|c|}
\hline \multirow[b]{2}{*}{ Año } & \multirow[b]{2}{*}{$\begin{array}{c}\text { Gobierno } \\
\text { general } \\
\left({ }^{*}\right)\end{array}$} & \multirow[b]{2}{*}{$\begin{array}{l}\text { Adminis- } \\
\text { tración } \\
\text { pública no } \\
\text { financiera }\end{array}$} & \multirow[b]{2}{*}{$\begin{array}{c}\text { Gobierno } \\
\text { general } \\
(\% \text { de } \\
\text { APNF })\end{array}$} & \multirow{2}{*}{$\begin{array}{c}\text { Gasto } \\
\text { (Gob. } \\
\text { Gral.) } \\
\text { (\% del } \\
\text { PIB) } \\
\end{array}$} & \multirow{2}{*}{\begin{tabular}{|c|} 
Gasto \\
consolidado \\
SPNF \\
(\% del \\
PIB) \\
\end{tabular}} & \multicolumn{3}{|c|}{ Tamaño de descentralización } \\
\hline & & & & & & $\begin{array}{c}\text { (GM+GD)/ } \\
\text { GT } \\
\text { (sin emp.) }\end{array}$ & $\begin{array}{c}\mathrm{GM} / \\
(\mathrm{GD}+\mathrm{GC})\end{array}$ & $\begin{array}{c}\mathrm{GM} / \\
(\mathrm{GM}+\mathrm{GD})\end{array}$ \\
\hline 1990 & $3.450,2$ & $5.427,2$ & 63,6 & 22,3 & 35,1 & 15,6 & 6,1 & 36,6 \\
\hline 1991 & $4.613,2$ & $7.009,2$ & 65,8 & 24,1 & 36,6 & 15,9 & 6,0 & 35,5 \\
\hline 1992 & $5.684,0$ & $8.260,4$ & 68,8 & 25,8 & 37,5 & 15,6 & 6,0 & 36,3 \\
\hline 1993 & $6.443,8$ & $9.104,5$ & 70,8 & 26,3 & 37,2 & 16,5 & 7,6 & 43,0 \\
\hline 1994 & $7.246,2$ & $10.074,1$ & 71,9 & 26,2 & 36,5 & 17,7 & 10,3 & 52,6 \\
\hline 1995 & $8.099,8$ & $11.027,7$ & 73,4 & 25,1 & 34,2 & 20,2 & 16,1 & 68,5 \\
\hline 1996 & $9.640,3$ & $12.145,3$ & 79,4 & 25,7 & 32,4 & 23,4 & 17,7 & 64,0 \\
\hline 1997 & $11.381,5$ & $14.049,4$ & 81,0 & 27,3 & 33,7 & 24,3 & 17,5 & 61,4 \\
\hline 1998 & $13.640,0$ & $16.832,2$ & 81,0 & 29,1 & 35,9 & 25,3 & 19,2 & 63,5 \\
\hline 1999 & $14.131,4$ & $17.375,9$ & 81,3 & 29,3 & 36,1 & 21,9 & 18,4 & 71,1 \\
\hline 2000 & $15.089,6$ & $19.434,6$ & 77,6 & 29,1 & 37,4 & 21,1 & 15,7 & 64,5 \\
\hline 2001 & $16.968,4$ & $20.062,4$ & 84,6 & 31,5 & 37,3 & 24,7 & 16,3 & 56,8 \\
\hline 2002 & $18.601,7$ & $20.716,1$ & 89,8 & 32,8 & 36,5 & 23,2 & 19,4 & 70,0 \\
\hline 2003 & $19.604,3$ & $22.717,9$ & 86,3 & 31,7 & 36,7 & 22,3 & 19,1 & 71,9 \\
\hline 2004 & $22.264,9$ & $23.710,4$ & 93,9 & 32,0 & 34,1 & 24,1 & 21,7 & 73,9 \\
\hline 2005 & $25.174,1$ & $26.088,3$ & 96,5 & 32,7 & 33,9 & 24,1 & 18,0 & 63,2 \\
\hline 2006 & $26.810,0$ & $31.727,8$ & 84,5 & 29,2 & 34,6 & 33,4 & 25,1 & 60,0 \\
\hline 2007 & $31.406,4$ & $43.144,4$ & 72,8 & 30,5 & 41,9 & 35,3 & 28,3 & 62,6 \\
\hline 2008 & $39.525,3$ & $54.478,2$ & 72,6 & 32,7 & 45,1 & 32,5 & 28,9 & 69,1 \\
\hline 2009 & $42.405,3$ & $56.584,1$ & 74,9 & 34,8 & 46,5 & 34,5 & 29,6 & 66,2 \\
\hline 2010 & $42.553,7$ & $59.256,5$ & 71,8 & 30,9 & 43,0 & 29,1 & 24,0 & 66,6 \\
\hline 2011 & $56.358,3$ & $74.232,5$ & 75,9 & 33,9 & 44,7 & 26,4 & 22,3 & 69,3 \\
\hline 2012 & $62.174,6$ & $84.702,0$ & 73,4 & 33,2 & 45,3 & 31,6 & 26,8 & 66,8 \\
\hline
\end{tabular}

Fuente: Elaboración propia a base de datos del dossier fiscal del Min. de Economía y Finanzas de Bolivia y del Anuario estadístico de UDAPE.

Referencias: GM: gobiernos municipales; GD: gobiernos departamentales; GC: gobierno central.

(*) El gobierno general incluye al gobierno central, gobiernos autónomos departamentales y municipales, más seguridad social. No incluye a las empresas públicas. 


\section{TABLA 13}

ESTRUCTURA FISCAL VERTICAL DE BOLIVIA (2012)

\begin{tabular}{|c|c|c|c|c|c|c|}
\hline \multirow{2}{*}{$\begin{array}{l}\text { Nivel de } \\
\text { Gobierno }\end{array}$} & \multicolumn{3}{|c|}{ En $\%$ del PIB } & \multicolumn{3}{|c|}{ Estructura \% } \\
\hline & Recursos & Gastos & $\begin{array}{l}\text { Result. } \\
\text { Financ. }\end{array}$ & Recursos & Gastos & $\begin{array}{l}\text { Result. } \\
\text { Financ. }\end{array}$ \\
\hline $\begin{array}{l}\text { Gobierno } \\
\text { Central }\end{array}$ & 33,3 & 22,7 & 10,6 & 95 & 68,4 & 578,7 \\
\hline $\begin{array}{l}\text { Gobiernos } \\
\text { Departamentales }\end{array}$ & 0,2 & 3,5 & $-3,3$ & 0,5 & 10,5 & $-180,8$ \\
\hline $\begin{array}{l}\text { Gobiernos } \\
\text { Municipales }\end{array}$ & 1,6 & 7 & $-5,4$ & 4,5 & 21,1 & $-297,8$ \\
\hline Total & 35,1 & 33,2 & 1,8 & 100 & 100 & 100 \\
\hline
\end{tabular}

Fuente: Elaboración propia a base de datos del Min. de Econ. y Finanzas de Bolivia.

\section{TABLA 14}

INDICADOR AGREGADO DE EFICIENCIA, CORRESPONDENCIA FISCAL Y TRANSFERENCIAS PER CAPITA

Base total $=100$. Año 2012

\begin{tabular}{|l|r|r|r|r|r|}
\hline \multirow{2}{*}{ Departamento } & \multirow{2}{*}{ Eficiencia } & $\begin{array}{c}\text { Correspondencia } \\
\text { fiscal }\end{array}$ & \multicolumn{3}{|c|}{$\begin{array}{c}\text { Transferencias per cápita } \\
\text { (a dptos. y municipios) }\end{array}$} \\
\cline { 4 - 6 } & & & LPP (Copart.) & $\begin{array}{c}\text { Recursos } \\
\text { naturales }\end{array}$ & Total \\
\hline Chuquisaca & 57,8 & 111,3 & 29,8 & 86,2 & 116,0 \\
La Paz & 105,2 & 162,4 & 29,8 & 24,5 & 54,4 \\
Cochabamba & 85,5 & 29,5 & 29,8 & 35,4 & 65,2 \\
Oruro & 111,8 & 41,5 & 29,8 & 91,9 & 121,7 \\
Potosí & 55,8 & 38,2 & 29,8 & 92,2 & 122,0 \\
Tarija & 204,7 & 17,2 & 29,8 & 421,7 & 451,5 \\
Santa Cruz & 142,8 & 131,8 & 29,8 & 40,0 & 69,9 \\
Beni & 59,6 & 116,6 & 29,8 & 120,4 & 150,2 \\
Pando & 78,2 & 121,5 & 29,8 & 395,1 & 425,0 \\
\hline Total país & $\mathbf{1 0 0 , 0}$ & $\mathbf{1 0 0 , 0}$ & $\mathbf{2 9 , 8}$ & $\mathbf{7 0 , 2}$ & $\mathbf{1 0 0 , 0}$ \\
\hline
\end{tabular}




\section{Información económica de Bolivia. Indicadores seleccionados}

\begin{tabular}{|c|c|c|c|}
\hline Año & $\begin{array}{c}\text { Precio de exportación } \\
\text { del gas natural a } \\
\text { Argentina } \\
\text { (dólares por miles de } \\
\text { pies cúbicos) }\end{array}$ & $\begin{array}{c}\text { Ingresos tributarios } \\
\text { por hidrocarburos } \\
\text { (incluye regalías) } \\
\text { (\% del PIB) }(*)\end{array}$ & $\begin{array}{c}\text { Exportaciones + } \\
\text { Importaciones } \\
\text { (en \% del PIB) }\end{array}$ \\
\hline 2003 & 1,1 & 4,6 & 39,8 \\
2004 & 1,6 & 5,0 & 46,1 \\
2005 & 2,7 & 9,0 & 55,2 \\
2006 & 4,2 & 11,6 & 60,3 \\
2007 & 5,6 & 11,3 & 62,0 \\
2008 & 9,3 & 10,6 & 70,1 \\
2009 & 6,4 & 9,8 & 55,2 \\
2010 & 7,9 & 9,3 & 61,5 \\
2011 & 10,1 & 9,7 & 68,5 \\
2012 & 11,9 & 11,7 & 72,6 \\
\hline
\end{tabular}

Fuente: Elaboración propia a base de datos del dossier fiscal del Min. de Economía y Finanzas de Bolivia. (*) Incluye ingresos fiscales en concepto de IVA, IT, IEHD, IDH y regalías

\section{Descripción de fuentes de información utilizadas}

\section{Respecto del gasto público social}

La información acerca del gasto público social de Bolivia es elaborada por UDAPE, siguiendo una clasificación utilizada internacionalmente. Se dispone información de gasto público social para el agregado del universo administración pública no financiera para el período 1990 a 2010, de manera desagregada para los departamentos en el período 2000-2006, y para igual período se dispone de datos desagregados a nivel de municipios.

En la estructura del gasto público social por finalidades y niveles de gobierno para el período 2000-2004 se identifican algunos hechos estilizados:

- El gasto público social representa alrededor del $45 \%$ del gasto público total del sector público no financiero.

- El gasto en educación es el principal componente del gasto público social, representando en promedio el $37 \%$ en el período analizado. El gasto en protección social representa alrededor del $32 \%$ en promedio. En salud se asigna alrededor del $18 \%$ del total. El gasto en vivienda y servicios básicos representa en promedio el $10 \%$ del total del gasto.

- El nivel central de gobierno realiza el $46 \%$ del gasto público social. Las prefecturas ejecutan alrededor del $29 \%$ y los municipios el $14 \%$. En un nivel aparte se 
encuentra el gasto en concepto de seguridad social, representando alrededor del $9 \%$ del gasto público social.

- En líneas generales, el registro contable muestra a las prefecturas como el principal nivel de gobierno que gasta en salud y educación. Es posible aclarar que en estos niveles de gobierno se pagan los salarios con financiamiento del gobierno central, que a su vez toma las decisiones de gasto en estos sectores.

- El gasto en protección social es ejecutado básicamente por el gobierno central. En cambio, el gasto en vivienda y servicios básicos es ejecutado en su mayor parte por las municipalidades.

\section{Indicadores de desempeño}

Siguiendo la discusión conceptual planteada en la sección anterior, pueden identificarse indicadores representativos del resultado final de las políticas gubernamentales. Por ejemplo, un indicador de educación referido al número de individuos matriculados en un año no necesariamente puede reflejar una mejora en el nivel de educación alcanzado por la población que es el objetivo último de las políticas públicas.

Hecha esa distinción, se identificaron indicadores que estén más estrechamente asociados al resultado de las políticas públicas y que se vinculen con las funciones de gasto público social. Se tomaron en cuenta las funciones de salud, educación y vivienda y servicios básicos:

- Para salud: tasa de mortalidad infantil (niños menores de 1 año), tasa de mortalidad materna y esperanza de vida al nacer. Con estos indicadores se captura el impacto del gasto en salud sobre el estado sanitario de la población ${ }^{22}$.

- Para educación: años promedio de estudio para la población de 19 años de edad o más, tasa de analfabetismo. Estos indicadores reflejan el impacto del gasto educativo respecto del nivel y calidad de la educación de la población.

- Vivienda y servicios urbanos: porcentaje de viviendas que disponen de energía eléctrica conectada a la red, porcentaje de viviendas conectadas a la red de agua potable y porcentaje de viviendas con descarga al alcantarillado. Estos indicadores reflejan la provisión de bienes públicos a nivel local, donde los municipios tienen una participación importante.

Los indicadores fueron seleccionados para los años 1992, 2001 y 2012, ya que gran parte de estos provienen de los censos nacionales de población y vivienda. Esto permite desagregar la información a nivel de departamentos y municipios.

22 Las fuentes de información utilizadas son el Instituto Nacional de Estadísticas (INE) y la Unidad de Análisis de Políticas Sociales y Económicas UDAPE. 
